This document is the unedited Author's version of a Submitted Work that was subsequently accepted for publication in ACS Applied Materials \& Interfaces, copyright $\odot$ American Chemical Society after peer review. The reference of the final edited and published work is ACS Appl. Mater. Interfaces 2018, 10, 31, 26195-26205 and can be found at https://pubs.acs.org/doi/10.1021/acsami.8b05854

\title{
Microporous Polymer Networks for Carbon Capture Applications
}

Beatriz Lopez-Iglesias ${ }^{1}$, Fabián Suárez-García ${ }^{2}$, Carla Aguilar-Lugo ${ }^{3}$, Alfonso González Ortega $^{4}$, Camino Bartolomé ${ }^{1}$, Jesús M. Martínez-Ilarduya ${ }^{1}$, José G. de la Campa ${ }^{3}$, Ángel E. Lozano ${ }^{1,3,5^{*}}$, Cristina Álvarez $3^{*}$

1. IU CINQUIMA, Universidad de Valladolid, Paseo Belén 5, E-47011 Valladolid, Spain.

2. Instituto Nacional del Carbón, INCAR-CSIC, Dr. Ingeniero Francisco Pintado 26, E-33011 Oviedo, Spain.

3. Department of Applied Macromolecular Chemistry, Instituto de Ciencia y Tecnología de Polímeros, ICTP-CSIC, Juan de la Cierva 3, E-28006 Madrid, Spain.

4. Department of Organic Chemistry, Universidad de Valladolid, Facultad de Ciencias, Paseo Belén 7, E47011 Valladolid, Spain.

5. SMAP, UA-UVA_CSIC, Associated Research Unit to CSIC. Universidad de Valladolid, Facultad de Ciencias, Paseo Belén 7, E-47011 Valladolid, Spain.

\section{Table of Content}

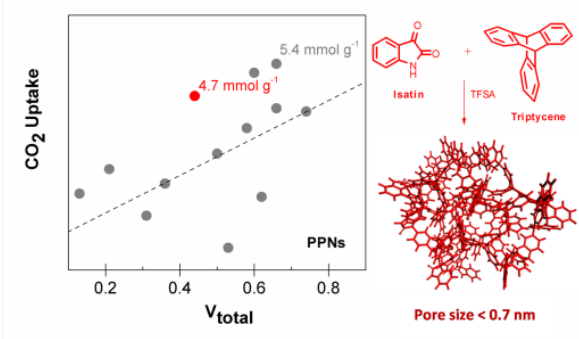

\section{Abstract}

A new generation of porous polymer networks, PPNs, has been obtained in quantitative yield by reacting in superacidic media two rigid trifunctional aromatic monomers $(1,3,5$ triphenylbenzene and triptycene) with two ketones having electron-withdrawing groups (trifluoroacetophenone and isatin). The resulting amorphous networks are microporous materials, with moderate BET surface areas (from 580 to $790 \mathrm{~m}^{2} \mathrm{~g}^{-1}$ ) and have high thermal stability. In particular, isatin yields networks with a very high narrow 
microporosity contribution, $82 \%$ for triptycene and $64 \%$ for 1,3,5-triphenylbenzene. The existence of favorable interactions between lactams and $\mathrm{CO}_{2}$ molecules has been stated. The materials show excellent $\mathrm{CO}_{2}$ uptakes (up to $207 \mathrm{mg} \mathrm{g}^{-1}$ at $0{ }^{\circ} \mathrm{C} / 1$ bar) and can be regenerated by vacuum, without heating. Under post-combustion conditions, their $\mathrm{CO}_{2} / \mathrm{N}_{2}$ selectivities are comparable to those of other organic porous networks. Because of the easily scalable synthetic method and their favorable characteristics, these materials are very promising as industrial adsorbents.

\section{INTRODUCTION}

The search of new materials able to revert in any form the global warming is mandatory for our civilization. Global warming is a serious risk for our society due to the expected calamitous effects in the environment and human health. Therefore, our society should, at least, maintain the $\mathrm{CO}_{2}$ atmospheric value as low as possible. ${ }^{1-6}$

Over the last few years, novel solid adsorbent materials have been explored to be used in carbon capture and storage (CCS) technologies, which have the greatest likelihood of reducing $\mathrm{CO}_{2}$ emissions to the atmosphere. ${ }^{7,8}$ An efficient solid adsorbent material should be highly selective towards $\mathrm{CO}_{2}$ over other gases present in the stream (notably $\mathrm{N}_{2}, \mathrm{H}_{2}$, $\mathrm{CH}_{4}$ and $\mathrm{H}_{2} \mathrm{O}$ ), have a high $\mathrm{CO}_{2}$ uptake capacity at low and high gas pressure, be physical and chemically stable under operational conditions, be easily regenerated with low energy input, maintain its performance under a humid atmosphere and repeated uses, and be prepared from low-cost raw materials.

In the search for efficient solid adsorbents for $\mathrm{CO}_{2}$ capture, the amorphous porous materials have garnered much attention in recent years. ${ }^{9-11}$ These materials are tailored using covalently linked molecular building blocks to possess high porosities and chemical

and physical stabilities. ${ }^{12}$ Moreover, these blocks are often derived from aromatic 
monomers, either linked directly or by other rigid groups, to prevent the networks from collapsing. These networks have been prepared using a great diversity of chemistry and have been named in many different ways, such as hyper-cross-linking polymers (HCPs), ${ }^{13-15}$ porous aromatic frameworks (PAFs), ${ }^{16-19}$ porous polymer networks (PPNs), ${ }^{20,21}$ polymeric organic frameworks (POFs), ${ }^{22}$ porous benzimidazolebenzoxazole- benzothiazole- linked polymers (BILPs, BOLPs and BTLPs), ${ }^{23-25}$ porous imine-linked polymers frameworks, ${ }^{26}$ covalent triazine-based frameworks (CTFs), ${ }^{27-29}$ or PIM-based networks. ${ }^{30}$ However, in many cases, the monomers employed have to carry several functional groups (formed by multi-steps reactions), which increases notably their cost and limits their use for practical applications.

Recently, the Scholl reaction, which is able to form $\mathrm{sp}^{2}-\mathrm{sp}^{2}$ aromatic bonds by using Lewis acids, has been described for the preparation of PPNs. ${ }^{31}$ This route is especially attractive because it allows access to polymer networks with high microporosity from available and inexpensive starting materials and reagents. ${ }^{32,33}$

Another promising reaction to prepare PPNs, which has never been used according to our knowledge, consists of the acid (Lewis or Brönsted) catalyzed condensation at low temperatures of ketones or aldehydes with aromatic compounds, which is described in the literature as the hydroxyalkylation reaction. ${ }^{34}$

It has been shown that acid-catalyzed condensation reaction of ketones with aromatic substrates initially produces tri-substituted alcohols, which undergo further protonation of the hydroxyl group and subsequent reaction with another molecule of arene to provide the corresponding tetra-substituted methane derivatives. However, the carbocationic nature of carboxonium ions is limited by strong electronic delocalization resulting from contributions of the oxonium forms. This restricts the reactions at the carbocationic center to those with efficient nucleophiles. Only a few microporous polymer networks of this 
type have been obtained by employing common ketones, strong Brönsted acids, electronrich aromatic moieties and high reaction temperatures. ${ }^{35}$

According to Olah's definition of superelectrophiles, under superacidic conditions, further protonation or protosolvation of the protonated aldehydes or ketones is possible, which leads to very reactive intermediates (superelectrophiles), that is, electrophiles of doubly electron-deficient (dipositive) nature whose reactivity significantly exceeds that of their parent monocations under conventional reaction conditions. ${ }^{36-38}$ This super-electrophilic or multi-ionic intermediate can undergo successive condensation reactions with weaker nucleophiles, and thus it is possible the reaction even with deactivated aromatic rings (Scheme 1).

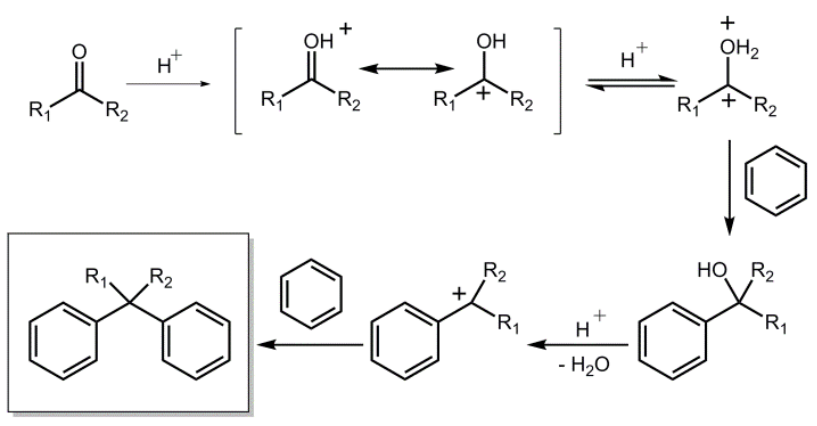

Scheme 1. Hydroxyalkylation reaction under superacidic conditions.

Irrespective of the mechanism, the reactivity of the protonated carbonyl group is further increased by the presence of electron-withdrawing groups (EWGs). For example, 1,2dicarbonyl groups form highly reactive intermediates in superacidic conditions. Carbonyl compounds bearing other electron-withdrawing substituents have been also used for this chemistry. For example, superacid-catalyzed condensation reactions of trifluoromethyl ketones occur with somewhat deactivated aromatic hydrocarbons to give diaryl derivatives in excellent yields. This is a well-known case of monocationic electrophile 
that reacts because the adjacent electron-withdrawing trifluoromethyl group enhances significantly the electrophylicity of the carbocation. ${ }^{39}$

Based on this high reactivity, Zolotukhin et al. have described the synthesis of high molecular weight, linear polymers, by reaction of activated ketones (2,2,2trifluoroacetophenone, isatin, ninhydrin, etc.) with several aromatic compounds, (biphenyl, p-terphenyl, p-quaterphenyl, biphenol, binaphtol, etc.), using superacids (trifluoromethanesulfonic acid, methanesulfonic acid, trifluoroacetic acid and mixtures of them).$^{40-44}$ It has been feasible to obtain polymers with high viscosity and excellent mechanical properties, by far better than those attained by other polymerization techniques that led to the same macromolecular structures. Moreover, the thermal and chemical stability of these polymers resulted to be very high. When the monomers are well chosen, it is possible to make easy chemical modification on the polymers: nitration, sulfonation, etc., what could bring about materials with tailor-made properties and with better ability to interact with specific molecules.

Therefore, in the present work, we have considered the reaction of trifunctional aromatic molecules having a specific symmetry (triptycene; a 3D paddle wheel structure having a $\mathrm{D}_{3 \mathrm{~h}}$ symmetry, and 1,3,5-triphenylbenzene, with a $\mathrm{C}_{3}$ symmetry), with activated ketones (1H-indole-2,3-dione, named isatin, and 2,2,2-trifluoroacetophenone), which act as bifunctional monomers, to prepare crosslinked, rigid, amorphous, tridimensional networks, designed to yield nanoporous materials with high fractional free volume (Scheme 2). The proposed reaction is very easy to carry out with high conversion, and it is possible to scale-up this methodology to produce high amounts of materials. The influence of the monomeric structure on the porosity and surface area of the networks has been studied along with their ability to take a high amount of $\mathrm{CO}_{2}$. 


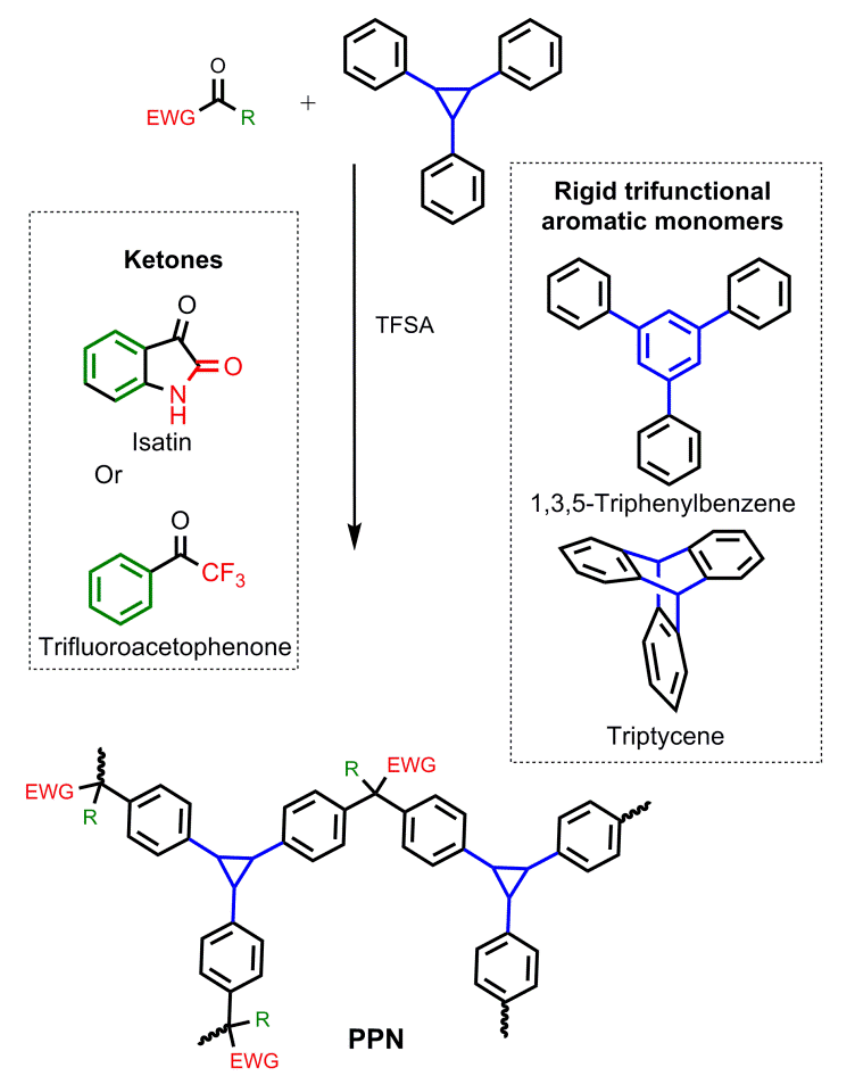

Scheme 2. Synthesis of tridimensional networks by reaction of a trifunctional arene with a difunctional carbonyl compound bearing electron-withdrawing groups (EWGs).

\section{EXPERIMENTAL PART}

\subsection{Materials}

Acetophenone (99\%), silicon tetrachloride (99\%), isatin (1H-indole-2,3-dione) (99\%), 2,2,2-trifluoroacetophenone (TFAP, 99\%), and anhydrous chloroform were purchased from Sigma-Aldrich. TFAP was previously distilled and stored in a Schlenk tube under nitrogen atmosphere. Isatin was dried at $60{ }^{\circ} \mathrm{C}$ for $2 \mathrm{~h}$, under vacuum, before use. Trifluromethanesulfonic acid (TFSA) (99\%) was supplied by Apollo Scientific, and triptycene (98\%) was purchased from abcr $\mathrm{GmbH}$. 
Synthesis of 1,3,5-triphenylbenzene (1,3,5-TPB). In a $100 \mathrm{~mL}$ double-jacket glass reactor equipped with magnetic stirring and a condenser, silicon tetrachloride ( $28 \mathrm{~mL}, 0.25 \mathrm{~mol})$ was added dropwise to a solution of acetophenone $(10.00 \mathrm{~g}, 0.083 \mathrm{~mol})$ in absolute ethanol $(60 \mathrm{~mL})$ at $0{ }^{\circ} \mathrm{C}$ and a white precipitate was formed immediately. The reaction mixture was then refluxed for $12 \mathrm{~h}$ to ensure the complete formation of the product. After cooling to room temperature, the white product was filtered, washed with cold ethanol, recrystallized from isopropanol and dried at $120{ }^{\circ} \mathrm{C}$ for $3 \mathrm{~h}$ under vacuum. Yield $72 \%$; ${ }^{1} \mathrm{H}$ NMR (300 MHz, DMSO-d6): $\delta(\mathrm{ppm}) 7.87$ (s, 3H), 7.85 (d, 6H), 7.51 (dd, 6H), 7.40 (dd, $3 \mathrm{H})$.

\subsection{Synthesis of the Porous Polymers Networks (PPNs)}

All the PPNs were synthesized in the same way, by combining triptycene and 1,3,5-TPB with isatin and TFAP. The reaction yields, in all cases, were higher than $95 \%$. As an example, the preparation of the Triptycene-Isatin network is described below:

An oven-dried three-necked, $50 \mathrm{~mL}$, Schlenk flask equipped with a mechanical stirrer and gas inlet and outlet was charged with triptycene (3.49 g, $13.8 \mathrm{mmol})$, isatin (3.06 g, $20.8 \mathrm{mmol})$ and chloroform $(15 \mathrm{~mL})$. The mixture was stirred at room temperature under a nitrogen blanket, cooled to $0{ }^{\circ} \mathrm{C}$ and trifluoromethanesulfonic acid $(30 \mathrm{~mL})$ was then slowly added with an addition funnel for 15-20 min. The reaction mixture was allowed to warm to room temperature and stirred for 5 days. The product was poured into a water/ethanol mixture (3/1), filtered and consecutively washed with water, acetone and chloroform. After drying at $150^{\circ} \mathrm{C}$ for $12 \mathrm{~h}$ in vacuum, the material was obtained as a tan powder in $97.5 \%$ yield. 


\subsection{Techniques}

Fourier Transform Infrared (FT-IR) spectra were registered on a Perkin Elmer Spectrum RX-I FT-IR spectrometer, equipped with an ATR accessory. Solid state ${ }^{13} \mathrm{C}$ crosspolarization magic angle spinning NMR spectra (CP-MAS ${ }^{13} \mathrm{C}$ NMR) were recorded on a Bruker Avance 400 spectrometer equipped with a $89 \mathrm{~mm}$ wide bore and a $9.4 \mathrm{~T}$ superconducting magnet. The spectrometer operated at a Larmor frequency of $100 \mathrm{MHz}$ using a contact time of $1 \mathrm{~ms}$ and a delay time of $3 \mathrm{~s}$. All samples were spun at $9 \mathrm{KHz}$. Thermogravimetric analysis (TGA) was performed on a TA-Q500 analyzer under nitrogen flux $\left(60 \mathrm{~mL} \mathrm{~min}^{-1}\right)$ at $10^{\circ} \mathrm{C} \mathrm{min}^{-1}$. Wide-angle-X-ray scattering (WAXS) patterns were recorded in the reflection mode at room temperature, using a Bruker D8 Advance diffractometer provided with a Goebel Mirror and a PSD Vantec detector. $\mathrm{CuK}_{\alpha}$ (wavelength $\lambda=1.54 \AA$ ) radiation was used. A step-scanning mode was employed for the detector, with a $2 \theta$ step of $0.024^{\circ}$ and $0.5 \mathrm{~s}$ per step. Scanning electron microscopy (SEM) images were taken with a QUANTA 200 FEG ESEM on Au-metallized samples operating at an acceleration voltage of $1.5 \mathrm{kV}$ in high vacuum and using the detection of secondary electrons method.

Porous texture characterization of the polymers was carried out from their $\mathrm{N}_{2}$ adsorptiondesorption isotherms measured at $-196{ }^{\circ} \mathrm{C}(77 \mathrm{~K})$ in a volumetric device ASAP 2010 (Micromeritics) in the $10^{-6}-0.995$ relative pressures $\left(\mathrm{P} / \mathrm{P}_{0}\right)$ range. The minimum equilibrium time (both for the adsorption and desorption) was 300 seconds. Samples were degassed at $125^{\circ} \mathrm{C}$ for $18 \mathrm{~h}$ under vacuum, before the sorption measurements, to eliminate the sample humidity and any other adsorbed gases. The adsorption branch of the isotherms was used to obtain the apparent surface area $\left(\mathrm{S}_{\mathrm{BET}}\right)$ by applying the Brunauer-Elmmett-Teller method in the 0.01 to $0.2 \mathrm{P} / \mathrm{P}_{0}$ range, the micropore volume ( $\mathrm{V}_{\text {micro }}$ ) using the Dubinin-Radushkevich (DR) equation in the 0.001 to 0.2 range and the 
total pore volume $\left(\mathrm{V}_{\text {total }}\right)$ as the volume of liquid nitrogen adsorbed at 0.975 relative pressure.

The $\mathrm{CO}_{2}$ adsorption capacities of the polymers at 0 and $25^{\circ} \mathrm{C}(273$ and $298 \mathrm{~K})$ were measured in a volumetric device Nova 4200 (Quantachrome). Samples were also degassed at $125^{\circ} \mathrm{C}$ for $18 \mathrm{~h}$ under vacuum before the $\mathrm{CO}_{2}$ adsorption measurements. From the $\mathrm{CO}_{2}$ adsorption isotherms at $0{ }^{\circ} \mathrm{C}$, the narrow micropore volume $\left(\mathrm{V}_{\text {nmicro, }}\right.$, pore width smaller than about $0.7 \mathrm{~nm}$ ) was obtained by applying the DR equation in the $10^{-4}$ to 0.03 $\mathrm{P} / \mathrm{P}_{0}$ range. The cumulative pore volume and the pore size distributions were also obtained from the $\mathrm{CO}_{2}$ isotherms at $0{ }^{\circ} \mathrm{C}$ by the NL-DFT method.

$\mathrm{N}_{2}$ and $\mathrm{CO}_{2}$ adsorption-desorption isotherms up to 30 bar were measured gravimetrically at $25^{\circ} \mathrm{C}$ in a high pressures magnetic suspension balance (Rubotherm). The samples were degassed in situ in the balance, at $120^{\circ} \mathrm{C}$ under vacuum until constant weight. The buoyancy effects related to the gas displacement by the sample, sample holder, and other balance components were corrected by means of helium displacement. ${ }^{45,46}$

\section{RESULTS AND DISCUSSION}

\subsection{Synthesis and characterization of PPNs}

The synthesis of porous polymer networks was accomplished by treatment of triptycene or 1,3,5-triphenylbencene (1,3,5-TPB), which acted as trifunctional nucleophilic monomers, with isatin or 2,2,2-trifluoroacetophenone (TFAP), which acted as bifunctional electrophilic ones, in the presence of a mixture of trifluoromethanesulfonic acid and chloroform for 5 days at room temperature. Under superacidic conditions, the ketone derivatives containing electron-withdrawing groups were first activated through protonation, followed by electrophilic aromatic substitution on the aromatic system. The 
combination of activated carbonyl compounds bearing electron-withdrawing groups and superacidic conditions permitted to assure a good reactivity and all of the PPNs were obtained with almost quantitative yields. To achieve the complete reaction, the proportion of trifunctional monomer to bifunctional one was kept at $2 / 3$.

As expected, the obtained PPNs were insoluble in organic solvents and even in very low $\mathrm{pK}_{\mathrm{a}}$ acids. Their chemical structures were characterized by ATR-FTIR (Figure 1) and $\mathrm{CP} / \mathrm{MAS}{ }^{13} \mathrm{C}$ NMR (Figure 2). The absorption bands at 1708,1469 , and $1320 \mathrm{~cm}^{-1}$ in the spectra of the isatin-based networks demonstrated the existence of 5-membered lactam rings coming from the isatin. The appearance of a broad band in the $3000-3600 \mathrm{~cm}^{-1}$ region was assigned to humidity traces in the samples, favored by the sorption of the amide groups (Figure S1 in the Supporting Information section). However, the presence of a small amount of tertiary alcohols, which were formed in the first stage of reaction (Scheme 1), could also be possible, if they have not undergone the ulterior protonation to provide the corresponding tetra-substituted methane derivatives. In the case of networks derived from TFAP, the absence of the carbonyl group band at about $1730 \mathrm{~cm}^{-1}$ and of the hydroxyl stretching bands above $3000 \mathrm{~cm}^{-1}$ confirmed the complete conversion of the ketone monomer. CP/MAS ${ }^{13} \mathrm{C}$ NMR spectra of Triptycene-Isatin and 1,3,5-TPB-TFAP are shown as examples in Figure 2. In all the systems, the peaks at 100-160 ppm were ascribed to carbon atoms in the aromatic rings and the peak at $62 \mathrm{ppm}$ was assigned to the quaternary carbon at the ketone moiety, which was formed during the reaction. Additionally, other peaks at 180 and $55 \mathrm{ppm}$ corresponding to the carbonyl groups of lactam rings and the methylidyne bridge carbons, respectively, were also seen. 


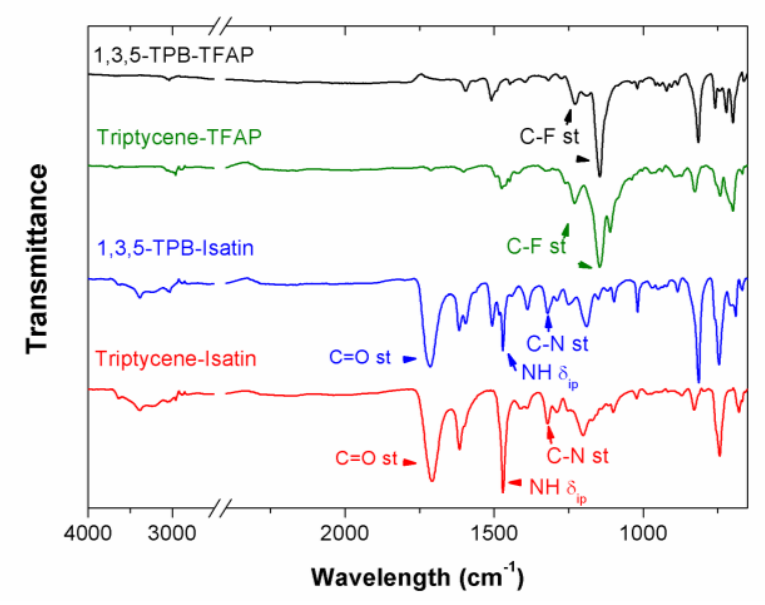

Figure 1. ATR-FTIR spectra of the PPNs.
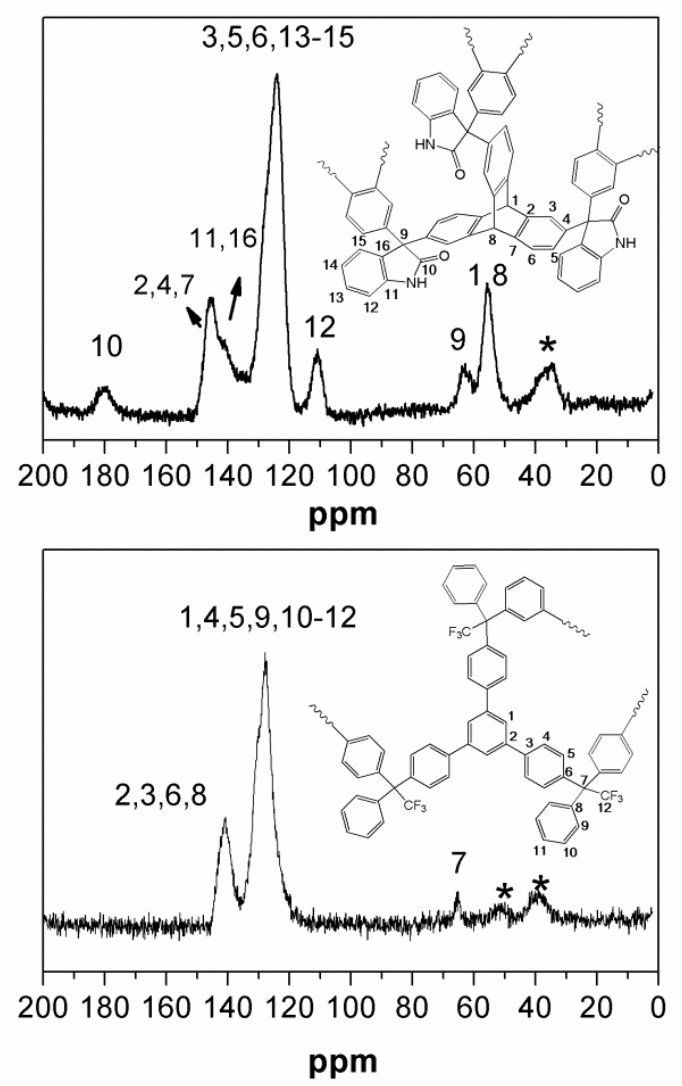

Figure 2. Solid state CP-MAS ${ }^{13} \mathrm{C}$ NMR spectra of Triptycene-Isatin (up) and 1,3,5-TPBTFAP (bottom). Asterisks denote spinning side bands.

Wide-angle powder X-ray diffraction (Figure 3) confirmed that all networks were amorphous, although those containing 1,3,5-TPB showed some regularity in the chains packing, with at least two clear preferential intersegmental distances at $13.9^{\circ}$ and $18.9^{\circ}$ 


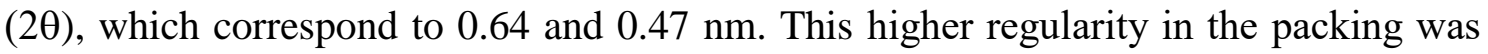
related to the planar-triangular shape of $1,3,5$-TPB because it could favor the formation of $\pi-\pi$ stacking into the network.

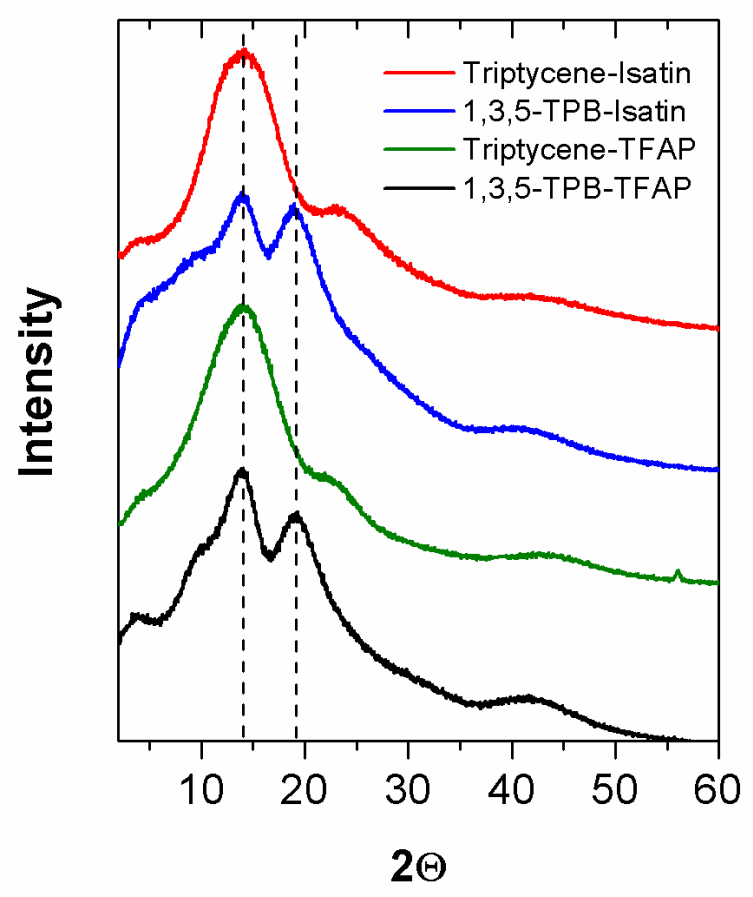

Figure 3. Wide-angle X-ray diffractograms of the PPNs.

The surface morphologies of the four PPNs were examined by FE-SEM (Figure 4). Triptycene-Isatin and Triptycene-TFAP networks consisted of loose agglomerates of tiny particles with rough surfaces and irregular shapes. 1,3,5-TPB-Isatin network was made up of spherical particles of very variable size. In contrast with the other PPNs, the images of 1,3,5-TPB-TFAP network revealed a homogeneous rough surface in which neither agglomerates nor particles were distinguished, probably due to the presence of very small size particles. 

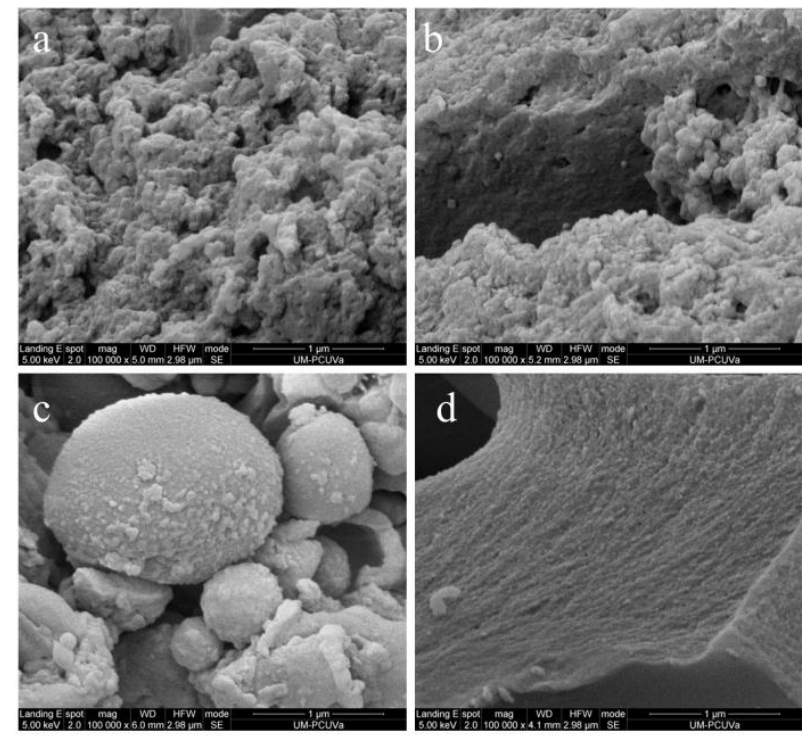

Figure 4. FE-SEM images of the PPNs: (a) Triptycene-Isatin, (b) 1,3,5-TPB-Isatin, (c) Triptycene-TFAP, and (d) 1,3,5-TPB-TFAP.

The resulting networks showed superb thermal stability both in nitrogen and in air atmosphere, as revealed by TGA (Figure 5). The degradation temperatures in both atmospheres and the char yield at $800{ }^{\circ} \mathrm{C}$ in nitrogen are listed in Table 1 . The char yields were very high, about $75 \%$ in all samples, as expected for highly aromatic systems having no hinges between the aromatic rings.

Table 1. Parameters of thermal stability of the PPNs.

\begin{tabular}{c|ccc} 
PPN & $\mathrm{R}_{800{ }^{\circ} \mathrm{C}^{\mathrm{a}}}$ & \multicolumn{2}{c}{ Degradation Temperature } \\
& & Nitrogen & Air \\
Triptycene-Isatin & 75 & 520 & 425 \\
1,3,5-TPB-Isatin & 74 & 535 & 465 \\
Triptycene-TFAP & 74 & 490 & 430 \\
1,3,5-TPB-TFAP & 76 & 500 & 470
\end{tabular}

${ }^{\text {a }}$ char yield at $800{ }^{\circ} \mathrm{C}(\%)$ in nitrogen atmosphere. ${ }^{\mathrm{b}}$ Temperature $\left({ }^{\circ} \mathrm{C}\right)$ corresponding to a $2 \%$ mass loss. 


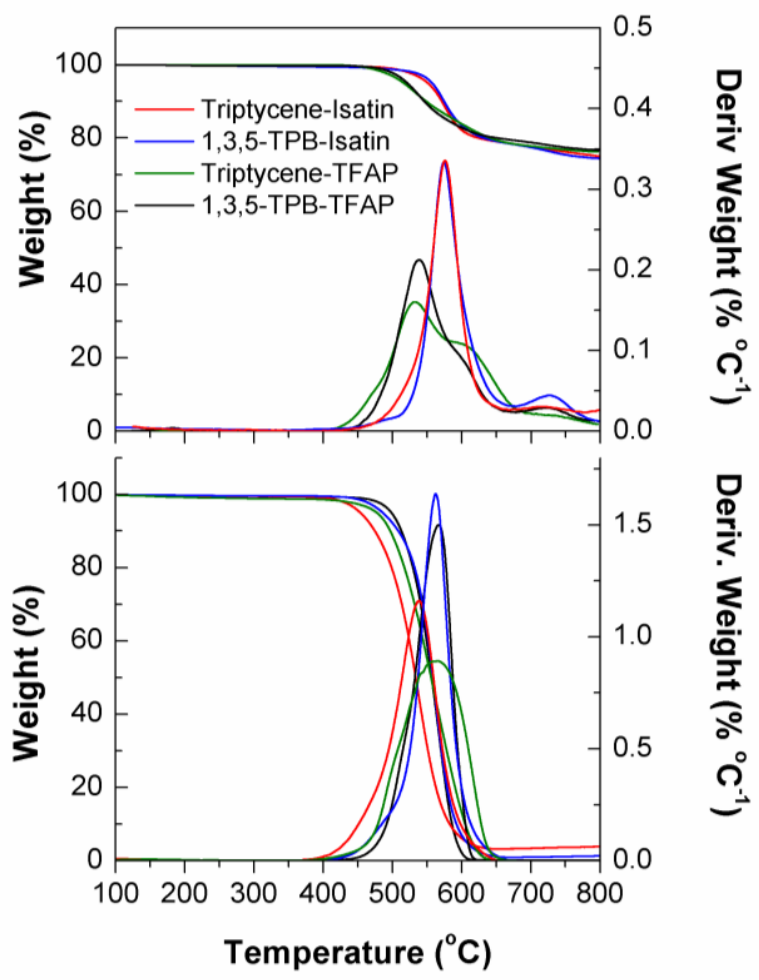

Figure 5. TGA thermograms of the PPNs in nitrogen (up) and in air (bottom) atmosphere.

\subsection{Porosity characterization}

The porosity of the PPNs was investigated by low-pressure sorption measurements using $\mathrm{N}_{2}$ at $-196^{\circ} \mathrm{C}$. The adsorption/desorption isotherms of the samples are displayed in Figure 6. All the PPNs showed a sharp uptake at low relative pressures $\left(\mathrm{P} / \mathrm{P}_{\mathrm{o}}<0.01\right)$ in the adsorption branch, implying a significant microporosity. However, unlike the microporous materials, which exhibit type I isotherms, according to IUPAC classification, ${ }^{47}$ the adsorption branch did not reach a plateau when the relative pressure increased (typically between $0.2 \leq \mathrm{P} / \mathrm{P}_{\mathrm{o}} \leq 0.8$ ) and the desorption branch showed a remarkable hysteresis down to low relative pressures. The slope between 0.2 and 0.8 , and the volume difference between the adsorption and desorption branches was higher in the case of Triptycene-TFAP. As a result, the additional $\mathrm{N}_{2}$ uptake at a relative pressure $\mathrm{P} / \mathrm{P}_{0}$ $=0.2$ was $21 \%$ for networks prepared with isatin, $27 \%$ for $1,3,5$-TPB-TFAP and $33 \%$ for Triptycene-TFAP. This behavior has already been reported for microporous networks, but 
no detailed understanding has been achieved so far. The low-pressure hysteresis has been usually attributed to swelling phenomena or to restricted diffusional access in very narrow micropores. The first case is associated to a dual-mode sorption model, where the pores are first filled with gas molecules, and an additional Henry sorption, which is proportional to the pressure, occurs due to swelling (formation of new pores or growth in size of preexistent ones). ${ }^{48}$ The second one is related to diffusional aspects (restricted filling of preexistent pores) due to the microporous morphology. ${ }^{49}$ In this context, the possible causes of hysteresis in these PPNs will be discussed along the section.

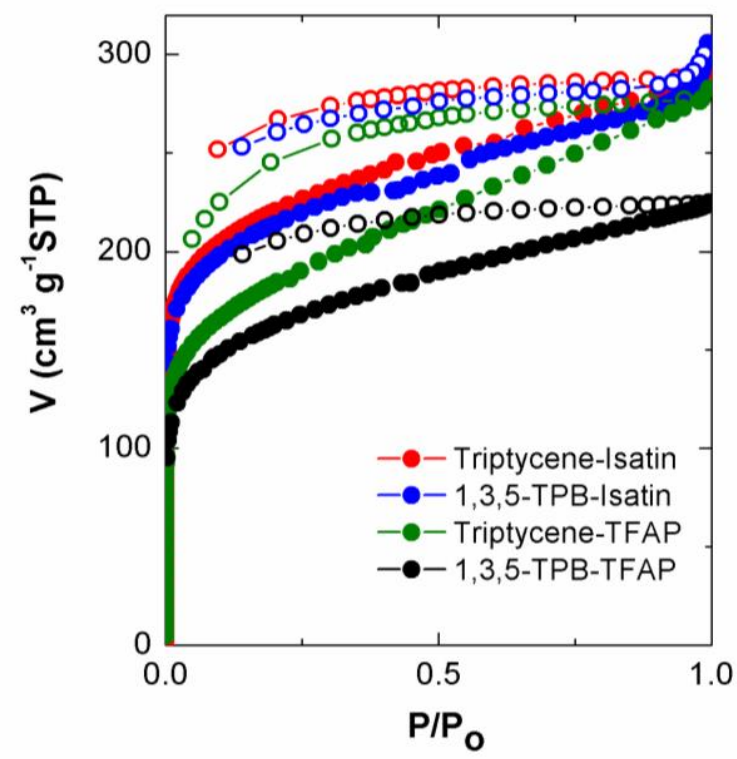

Figure 6. $\mathrm{N}_{2}$ adsorption (full symbols)/desorption (empty symbols) isotherms measured at $-196^{\circ} \mathrm{C}$ for the PPNs.

Here we want to point out that the equilibration times for the $\mathrm{N}_{2}$ isotherms were long enough to allow filling and emptying the micropores (pore width $<2 \mathrm{~nm}$ ). To verify it, two isotherms were obtained varying the equilibrium time (300 or 1200 seconds) and fixing the minimum equilibration delay in each of the points at low relative pressures $\left(\mathrm{P} / \mathrm{P}_{0}<0.2\right)$ as 1 and 10 hours. The effect of the equilibrium time on the amount of $\mathrm{N}_{2}$ adsorbed for Triptycene-TFAP, the network with the highest hysteresis, is shown in Figure 
7. The increase in the equilibrium setting allowed a slight rise in the amount of $\mathrm{N}_{2}$ adsorbed at the lowest relative pressures $\left(\mathrm{P} / \mathrm{P}_{0}<0.01\right)$, confirming the existence of diffusional limitations caused by restricted-access pores. Above that relative pressure, however, both isotherms overlapped, within the experimental error, and reached the same $\mathrm{N}_{2}$ uptake. Therefore, as no diffusional limitations can be detected when the pressure rises, the continuous increase of the slope is probably due to some swelling phenomena.

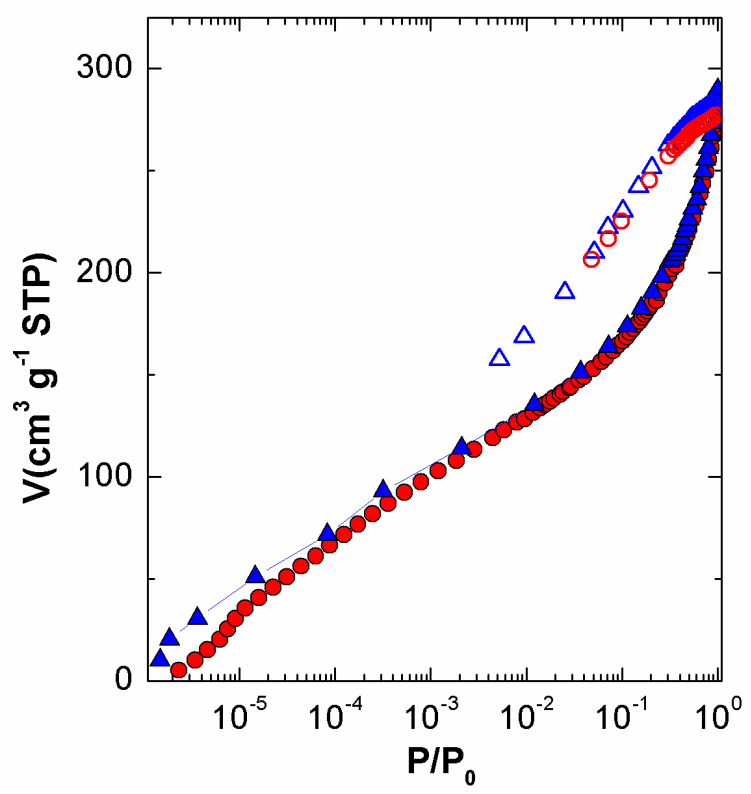

Figure 7. $\mathrm{N}_{2}$ adsorption (full symbols)/desorption (empty symbols) isotherms for Triptycene-TFAP PPN at $-196^{\circ} \mathrm{C}$ at different equilibrium time/minimum equilibration delay: $300 \mathrm{~s} / 1 \mathrm{~h}$ (circles) and $1200 \mathrm{~s} / 10 \mathrm{~h}$ (triangles).

In order to get insight into the microporosity of the samples, the $\mathrm{CO}_{2}$ adsorption/desorption isotherms of the PPNs at $0{ }^{\circ} \mathrm{C}$ and pressures up to 1 bar (Figure 8a) were also analyzed. The low-pressure $\mathrm{CO}_{2}$ adsorption at this temperature has been demonstrated as a complementary method for the characterization of the narrow microporosity of different adsorbents. ${ }^{50,51}$ The higher adsorption temperature, well above the $\mathrm{CO}_{2}$ condensation temperature of $-78^{\circ} \mathrm{C}$, results in a larger kinetic energy, decreasing the diffusion limitations in the narrow micropores. 

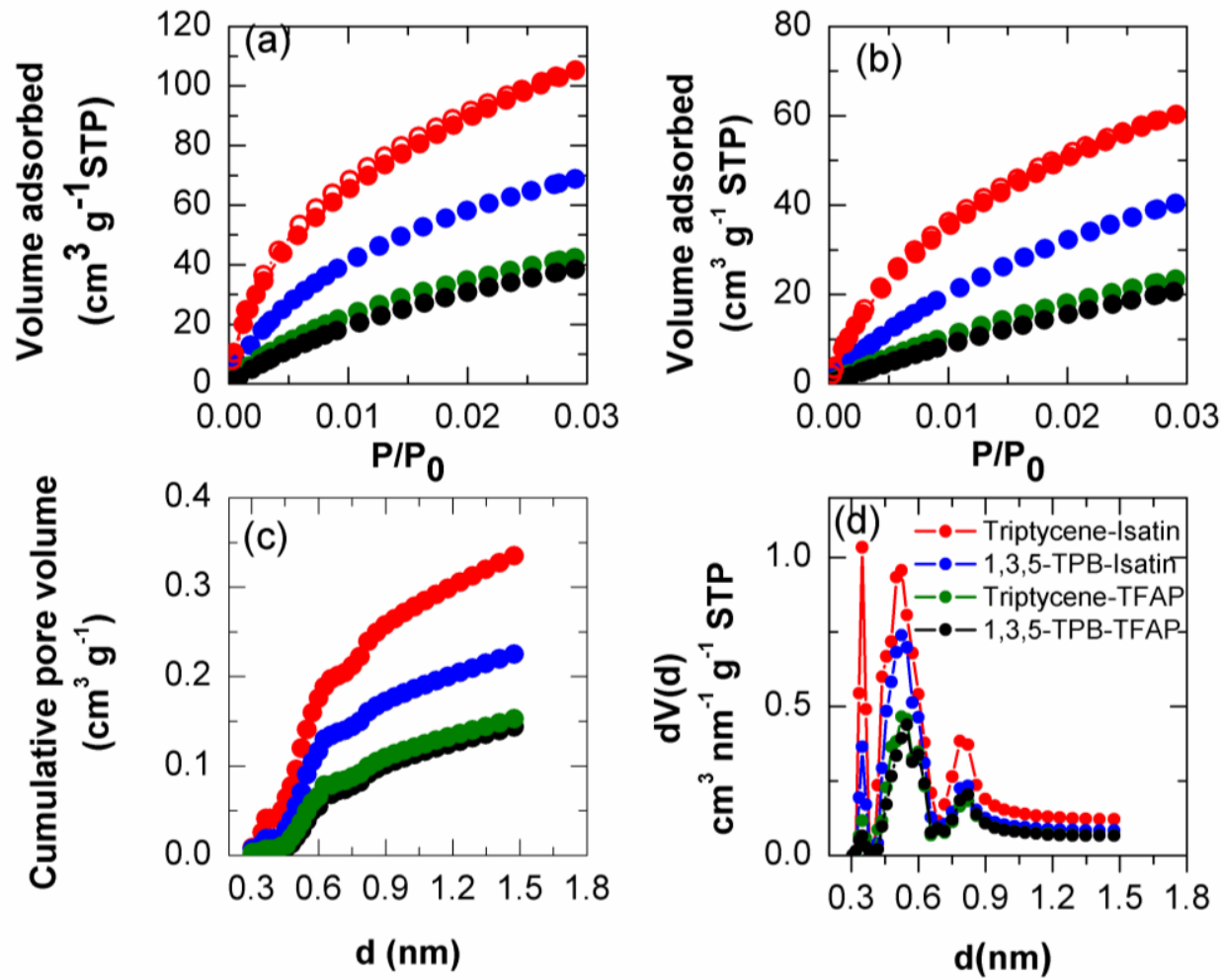

Figure 8. $\mathrm{CO}_{2}$ adsorption (full symbols)/desorption (empty symbols) at $0{ }^{\circ} \mathrm{C}$ (a) and 25 ${ }^{\circ} \mathrm{C}$ (b) of PPNs, cumulative pore volume (c) and narrow micropore-size distribution (d) obtained by DFT from the $\mathrm{CO}_{2}$ adsorption isotherms at $0{ }^{\circ} \mathrm{C}$.

The cumulative pore volume curves and the narrow micropore-size distribution, obtained by the method based on density functional theory (DFT), from the $\mathrm{CO}_{2}$ adsorption isotherms at $0{ }^{\circ} \mathrm{C}$, are shown in Figure 8 (c and d). The pore size distributions of the four PPNs exhibited three peaks: the first one at pore sizes lower than $0.4 \mathrm{~nm}$, the second one, of highest intensity, centered at $0.5 \mathrm{~nm}$ and the third one, of lowest intensity, at $0.8 \mathrm{~nm}$. The minimum at $0.4 \mathrm{~nm}$ might be due to an artifact of the DFT method, ${ }^{52}$ but, even if it were so considered, the networks presented a considerable contribution of narrow pores (smaller than $0.7 \mathrm{~nm}$ ). As it can be seen in Figure $8 \mathrm{c}$, Triptycene-Isatin has the highest volume of pores $<0.7 \mathrm{~nm}\left(0.20 \mathrm{~cm}^{3} \mathrm{~g}^{-1}\right)$, followed by $1,3,5$-TPB-Isatin $\left(0.14 \mathrm{~cm}^{3} \mathrm{~g}^{-1}\right)$, then by Triptycene-TFAP $\left(0.08 \mathrm{~cm}^{3} \mathrm{~g}^{-1}\right)$ and by $1,3,5$-TPB-TFAP $\left(0.07 \mathrm{~cm}^{3} \mathrm{~g}^{-1}\right)$. 
Therefore, the PPNs derived from isatin have the highest proportion of the narrowest micropores compared to those made from TFAP.

The porosity parameters obtained from $\mathrm{N}_{2}$ and $\mathrm{CO}_{2}$ adsorption at -196 and $0{ }^{\circ} \mathrm{C}$, respectively, for all the PPNs, are summarized in Table 2.

Table 2. Porosity parameters of PPNs from $\mathrm{N}_{2}$ and $\mathrm{CO}_{2}$ adsorption isotherms.

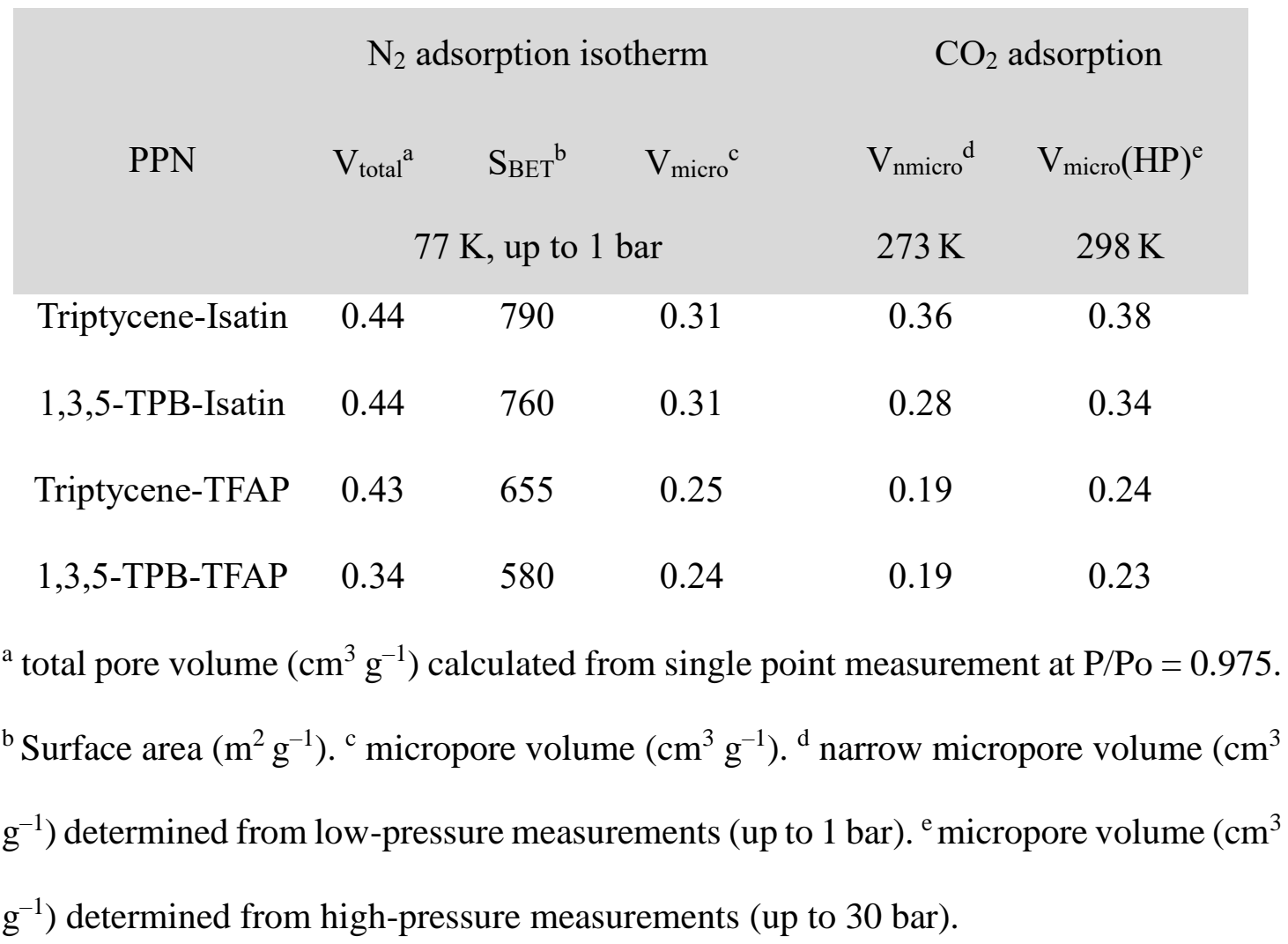

The $\mathrm{S}_{\mathrm{BET}}$ varied from 580 to $790 \mathrm{~m}^{2} \mathrm{~g}^{-1}$ and the highest values corresponded to the isatinbased PPNs, which also had the highest values of micropore volume. Moreover, the ratio between the volumes of narrow micropores $\left(\mathrm{V}_{\text {nmicro }}\right)$ and micropores accessible to $\mathrm{N}_{2}$ $\left(\mathrm{V}_{\text {micro }}\right)$ indicated that the micropore distribution seems to depend on the reacting ketone. Hence, for the case of isatin-based networks, in particular for Triptycene-Isatin PPN, there is a higher proportion of narrow micropores, many of them not accessible to the $\mathrm{N}_{2}$ $\left(\mathrm{V}_{\text {nmicro }}>\mathrm{V}_{\text {micro }}\right.$ ), while for the two TFAP-based ones, there is a significantly higher proportion of wider micropores $\left(\mathrm{V}_{\text {nmicro }}<\mathrm{V}_{\text {micro }}\right)$. 
The contribution of the narrow microporosity to the total pore volume $\left(\mathrm{V}_{\text {total }}\right)$ was estimated from $\mathrm{V}_{\text {nmicro, }}$, and the values are as follows: $82 \%$ for Triptycene-Isatin, $64 \%$ for 1,3,5-TPB-Isatin, $56 \%$ for $1,3,5$-TPB-TFAP and $44 \%$ for Triptycene-TFAP, confirming the microporous character of these polymers. The lower values shown for the two PPNs derived from TFAP, and especially for Triptycene-TFAP, could be due to a higher swelling of the network. Regardless of this fact, the results shown so far seem to indicate that isatin favors the formation of narrow micropores and, moreover, its combination with triptycene yields highly microporous networks.

\subsection{Low-pressures gas uptake of $\mathrm{CO}_{2}$}

The $\mathrm{CO}_{2}$ adsorption/desorption isotherms were also measured at $25^{\circ} \mathrm{C}$ and 1 bar (Figure 8b). The values of $\mathrm{CO}_{2}$ uptake at 0 and $25^{\circ} \mathrm{C}$ and 1 bar for all the PPNs, are listed in Table 3. The $\mathrm{CO}_{2}$ uptakes at $0{ }^{\circ} \mathrm{C}$ of the four PPNs showed the following order: TriptyceneIsatin had the highest value (207 $\left.\mathrm{mg} \mathrm{g}^{-1} / 4.70 \mathrm{mmol} \mathrm{g}^{-1}\right)$, followed by 1,3,5-TPB-Isatin (135 $\left.\mathrm{mg} \mathrm{g}^{-1} / 3.07 \mathrm{mmol} \mathrm{g}^{-1}\right)$, then by Triptycene-TFAP (83 $\mathrm{mg} \mathrm{g}^{-1} / 1.89 \mathrm{mmol} \mathrm{g}^{-1}$ ) and finally by $1,3,5$-TPB-TFAP $\left(76 \mathrm{mg} \mathrm{g}^{-1} / 1.72 \mathrm{mmol} \mathrm{g}^{-1}\right)$. As expected in a physisorption process, the adsorption capacity of $\mathrm{CO}_{2}$ decreased when temperature increased and was between 41 and $45 \%$ lower at $25{ }^{\circ} \mathrm{C}$. It is noteworthy that the $\mathrm{CO}_{2}$ adsorption at subatmospheric pressures was completely reversible for all the PPNs, indicating the possibility of regeneration of these materials by vacuum without applying heat.

Table 3. $\mathrm{CO}_{2}$ and $\mathrm{N}_{2}$ uptakes and isosteric heats of $\mathrm{CO}_{2}$ adsorption for PPNs.

\begin{tabular}{cccccc} 
PPN & \multicolumn{3}{c}{$\mathrm{CO}_{2}$ at $1 \mathrm{bar}^{\mathrm{a}}$} & $\mathrm{CO}_{2}$ at $30 \mathrm{bar}^{\mathrm{b}}$ & $\mathrm{N}_{2}$ at 30 \\
& 273 & $298 \mathrm{~K}$ & $\mathrm{Q}_{\mathrm{st}}$ & $298 \mathrm{~K}$ & $298 \mathrm{~K}$ \\
\hline Triptycene-Isatin & 207 & 118 & 35.3 & 407 & 52 \\
1,3,5-TPB-Isatin & 135 & 79 & 31.8 & 365 & 44
\end{tabular}




$\begin{array}{llllll}\text { Triptycene-TFAP } & 83 & 46 & 29.6 & 252 & 34 \\ 1,3,5 \text {-TPB-TFAP } & 76 & 40 & 28.3 & 247 & 33\end{array}$

${ }^{\mathrm{a}}$ Gas uptake $\left(\mathrm{mg} \mathrm{g}^{-1}\right)$ and isosteric enthalpies of adsorption, $\mathrm{Q}_{\mathrm{st}},\left(\mathrm{kJ} \mathrm{mol}^{-1}\right) .{ }^{\mathrm{b}}$ Excess gas uptake $\left(\mathrm{mg} \mathrm{g}^{-1}\right)$.

The $\mathrm{CO}_{2}$ uptakes at $0{ }^{\circ} \mathrm{C}$ of these PPNs can be compared with those of other networks containing triptycene or 1,3,5-TPB, such as azo-linked polymers (ALPs), (5.34-3.5 mmol $\left.\mathrm{g}^{-1}\right),{ }^{53}$ triazole-linked polymers (TNPs), $\left(4.5-1.6 \mathrm{mmol} \mathrm{g}^{-1}\right),{ }^{54}$ polybenzimidazole networks (TBIs), (3.2-2.7 mmol g-1 $),{ }^{55}$ benzimidazole-linked polymers (BILPs) (5.3-2.9 mmol g $\left.{ }^{-1}\right),{ }^{23}$ benzoxazole-linked polymers (BOLPs) $\left(3.1-2.9 \mathrm{mmol} \mathrm{g}^{-1}\right),{ }^{25}$ benzothiazolelinked polymers (BTLPs) (4.3-3.2), ${ }^{25}$ Porous aromatic frameworks (PAFs) (4.7-3.3), ${ }^{19}$ triazine-based benzimidazole-linked polymers (TBILPs), $\left(5.1-2.6 \mathrm{mmol} \mathrm{g} \mathrm{g}^{-1}\right),{ }^{24} \mathrm{star}$ triptycene-based microporous polymers (STPs) (4.1-3.7), ${ }^{56}$ and microporous polyimides (MPI), (3.8-2.3 mmol g $\left.{ }^{-1}\right) \cdot{ }^{57}$ Figure 9 compares the $\mathrm{CO}_{2}$ uptakes at $0{ }^{\circ} \mathrm{C}$ and 1 bar of the PPNs studied here and those previously reported containing triptycene (circles) or 1,3,5TPB (squares). The data are shown as a function of the total pore volumes, which were taken in the $\mathrm{P} / \mathrm{P}_{\mathrm{o}}$ range between 0.90 and 1 from the $\mathrm{N}_{2}$ or Ar adsorption isotherms. The scatter of the data was large and the linear correlation coefficient was poor $(r=0.17)$, indicating that the total pore volume is not the only factor that determines the $\mathrm{CO}_{2}$ uptake in these PPNs. The $\mathrm{CO}_{2}$ uptake of Triptycene-Isatin $\left(207 \mathrm{mg} \mathrm{g}^{-1}\right)$ was only about $10 \%$ lower than the two best values of the PPNs here considered, which correspond to ALP1 $\left(236 \mathrm{mg} \mathrm{g}^{-1}\right)^{53}$ and TBILP2 $\left(228 \mathrm{mg} \mathrm{g}^{-1}\right)^{24}$, although the total pore volumes of these two PPNs were considerably higher $\left(0.66\right.$ and $0.60 \mathrm{~cm}^{3} \mathrm{~g}^{-1}$, respectively). As far as we know, the $\mathrm{CO}_{2}$ uptake of ALP1 represents one of the highest values for all known porous organic polymers reported to date. Moreover, the adsorption capacity of all the other networks here considered was lower than that of Triptycene-Isatin, even though many of them have a significantly higher $\mathrm{V}_{\text {total. }}$. It should also be remarked that all the networks with $\mathrm{V}_{\text {total }}$ 
above $0.5 \mathrm{~cm}^{3} \mathrm{~g}^{-1}$ and high $\mathrm{CO}_{2}$ adsorption contain triptycene in their structure. This result is likely due to the rigid, fused-ring skeleton and three-fold symmetry structure of triptycene that provides a high internal molecular free volume and high surface area. As an example, the networks derived from STPs, which were obtained by a triptycenetriptycene coupling reaction from trihalotriptycenes, showed high BET surfaces $(>1300$ $\left.\mathrm{m}^{2} \mathrm{~g}^{-1}\right)$ and high total volumes and $\mathrm{CO}_{2}$ uptakes at $25^{\circ} \mathrm{C}$ and 1 bar, up to $4.0 \mathrm{mmol} \mathrm{g}^{-1} .{ }^{56}$ However, the microporosity ratio (defined as $V_{\text {micro }} / V_{\text {total }}$ ) was about 0.46 while it was 0.70 for Triptycene-Isatin PPN. Thus, the narrow microporosity would be a factor to consider in the high $\mathrm{CO}_{2}$ adsorption capacity of Triptycene-Isatin.

Another factor to be considered is the binding affinity of these PPNs to $\mathrm{CO}_{2} \cdot{ }^{58,59}$ The isosteric heats were determined by using the Clausius-Clapyeron equation (see Section 2 in the Supporting Information) from the data collected at 0 and $25^{\circ} \mathrm{C}$. The $\mathrm{Q}_{\mathrm{st}}$ values at zero coverage for the PPNs fell in a range between 28.3 and $35.3 \mathrm{~kJ} \mathrm{~mol}^{-1}$ (See Table 3). The highest values corresponded to the PPNs made from isatin, presumably due to the presence of lactam groups, which could interact favorably with $\mathrm{CO}_{2}$ molecules, and so contribute significantly to the high $\mathrm{CO}_{2}$ uptake.

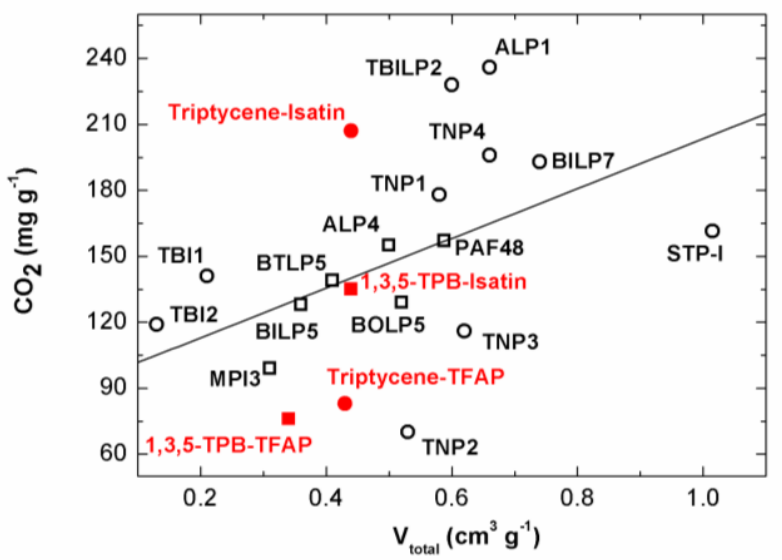


Figure 9. $\mathrm{CO}_{2}$ uptake as a function of total pore volume for the PPNs and several porous organic polymers containing triptycene or 1,3,5-TPB in their structure.

To assess the effect of lactam groups and fluorine atoms $\left(\mathrm{CF}_{3}\right.$ moieties $)$ on $\mathrm{CO}_{2}$ binding interactions, we performed a DFT quantum mechanical study of the energy of interaction of two models (derived from the reactions of isatin and TFAP with benzene: Isatin-model and TFAP-model) in the presence of $\mathrm{CO}_{2}$ (one and two molecules). All the details about the computational methods are provided in the Supporting Information section.

The electronic energy of the optimized geometries for both models and their $\mathrm{CO}_{2}$-adducts are listed in Table S1. A favorable interaction of both models with $\mathrm{CO}_{2}$ molecules was found. The binding affinity for the first $\mathrm{CO}_{2}$ molecule was significantly higher for the Isatin-model than for the TFAP-model $\left(20.741 \mathrm{vs} 9.681 \mathrm{~kJ} \mathrm{~mol}^{-1}\right)$. However, the introduction of the second $\mathrm{CO}_{2}$ molecule had roughly the same effect in the interaction energy for both models (around $11 \mathrm{~kJ} \mathrm{~mol}^{-1}$ ). The binding affinity was also been estimated from the deviation of the $\mathrm{OCO}$ angle from the value of $180^{\circ}$, corresponding to the isolated $\mathrm{CO}_{2}$. By comparing the values listed in the last column of Table $\mathrm{S} 1$, according to this criterion, the highest interaction corresponded to the Isatin-model- $1 \mathrm{CO}_{2}$ and to the first $\mathrm{CO}_{2}$ of the Isatin-model- $2 \mathrm{CO}_{2}$. In TFAP-model the interaction with $\mathrm{CO}_{2}$ was clearly lower in all cases, confirming the results obtained from the interaction energy.

Figure 10 shows the optimized geometry of the corresponding adducts with one and two molecules of $\mathrm{CO}_{2}$. The interactions of the first $\mathrm{CO}_{2}$ molecule with the Isatin-model (a) were through the $\mathrm{O}$ atom of the $\mathrm{C}=\mathrm{O}$ in the lactam ring and the $\mathrm{C}$ atom in the $\mathrm{CO}_{2}$ and through the $\mathrm{N}-\mathrm{H}$ group and the $\mathrm{O}$ atom in the $\mathrm{CO}_{2}$, with interatomic distances of 2.80 and $2.30 \AA$, respectively. For the TFAP-model (c), the $\mathrm{C}$ atom in the $\mathrm{CO}_{2}$ molecule interacted with two $\mathrm{F}$ atoms of the $\mathrm{CF}_{3}$ moiety (at distances of 2.97 and $3.07 \AA$ ). On the other hand, when two $\mathrm{CO}_{2}$ molecules were allowed to interact with each model, a different orientation 
of the $\mathrm{CO}_{2}$ molecules was observed in each case, t-shape for Isatin-model (b) and crossedshape for TFAP-model (d). In the Isatin-model, only one of the $\mathrm{O}$ atoms in the second $\mathrm{CO}_{2}$ molecule interacts with the lactam ring, through the N-H. In the TFAP-model, the second $\mathrm{CO}_{2}$ molecule interacted with the $\mathrm{F}$ atoms, in a way similar to the first one. Moreover, intermolecular interactions between both $\mathrm{CO}_{2}$ molecules, $\mathrm{O}=\mathrm{C}=\mathrm{O}(\delta$ ${ }^{\cdots} \cdot \mathrm{C}(\delta+) \mathrm{O}_{2}$, were found, with bond distances of 2.95 and $3.25 \AA$ for Isatin-model and TFAP-model, respectively. Consequently, this interaction should also favor the incorporation of successive $\mathrm{CO}_{2}$ molecules.

These results support that the PPNs derived from isatin interact more favorably with $\mathrm{CO}_{2}$ than those derived from TFAP, thus confirming the highest $\mathrm{CO}_{2}$ uptake of these networks, even for similar values of $\mathrm{V}_{\text {total }}$. However, considering that both the amount of lactam groups and the $\mathrm{V}_{\text {total }}$ are similar in the Triptycene-Isatin and 1,3,5-TPB-Isatin, the highest $\mathrm{CO}_{2}$ adsorption for the first PPN is most likely due to the higher contribution of the narrow micropores to the total microporosity in that case.

Besides, taking into account that the $\mathrm{Q}_{\text {st }}$ values were comparable to or even superior to those found for ALPs $\left[27.9-29.6 \mathrm{~kJ} \mathrm{~mol}^{-1}\right],{ }^{53}$ BILPs $\left[26.7-28.8 \mathrm{~kJ} \mathrm{~mol}^{-1}\right],{ }^{23}$ TBILPs $[29.0-$ $\left.35.6 \mathrm{~kJ} \mathrm{~mol}^{-1}\right]^{24}$ and TNPs $\left[34.8-38.5 \mathrm{~kJ} \mathrm{~mol}^{-1}\right],{ }^{54}$ no correlation between the adsorption capacity and the isosteric heat of adsorption could be drawn from Figure 9. Thus, the total microporosity and pore size distribution seem to play a more relevant role in the $\mathrm{CO}_{2}$ adsorption capacity of these organic porous networks at low pressures. 
a

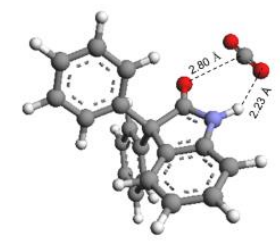

b

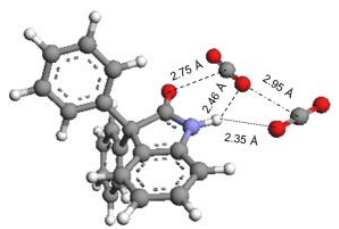

C

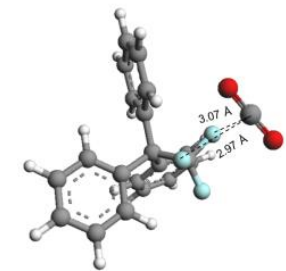

d

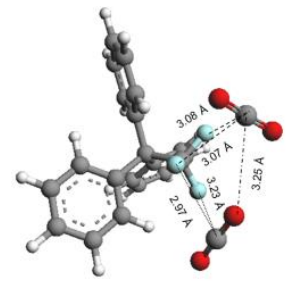

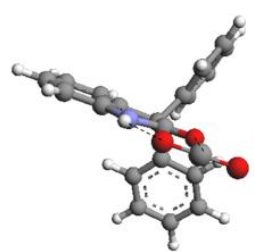
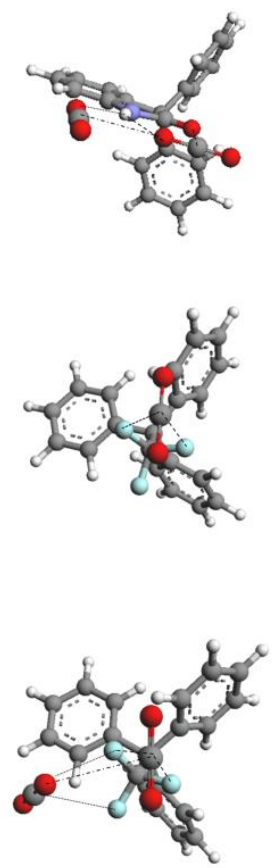

Figure 10. Optimized geometries for the $\mathrm{CO}_{2}$-adducts (one and two $\mathrm{CO}_{2}$ molecules) derived from Isatin-model ( $a$ and $b$ ) and TFAP-model ( $c$ and d). The lines are interatomic distances. The grey, white, red, blue and light-blue colors stand for $\mathrm{C}, \mathrm{H}, \mathrm{O}, \mathrm{N}$ and $\mathrm{F}$ atoms, respectively.

\subsection{High-pressures gas uptake of $\mathrm{CO}_{2}$ and $\mathrm{N}_{2}$}

The high-pressure adsorption/desorption isotherms of the PPNs for $\mathrm{N}_{2}$ and $\mathrm{CO}_{2}$ at $25{ }^{\circ} \mathrm{C}$ and up to 30 bar are displayed in Figure 11. For both gases, all the isotherms showed an increase in gas uptake with the increasing of gas pressure, without reaching a plateau, indicating that the pore volume filling was not complete over the pressure range considered. Despite the moderate $\mathrm{S}_{\mathrm{BET}}$ values, these materials showed good $\mathrm{CO}_{2}$ storage capacity, particularly those derived from isatin, as seen in Table 3. Triptycene-Isatin showed an excess $\mathrm{CO}_{2}$ uptake of 40.7 wt.\%, followed by 1,3,5-TPB-Isatin with a 36.5 
wt.\%, and then by the two TFAP-based PPNs with around $25 \mathrm{wt} . \%$ at 30 bar and $25^{\circ} \mathrm{C}$. These values were between 3.5 and 6.2 times higher than those obtained at 1 bar and 25 ${ }^{\circ} \mathrm{C}$. It is remarkable that the PPNs derived of TFAP underwent the highest increase in adsorption capacity when the pressure increased from 1 to 30 bar. On its turn, the sorption of $\mathrm{N}_{2}$ went from $5.2 \mathrm{wt} . \%$ for Triptycene-Isatin to $3.3 \mathrm{wt} . \%$ for the TFAP networks.

The high-pressure isotherms of $\mathrm{N}_{2}$ for the PPNs were completely reversible without any hysteresis loop, which was expected because the measurements were conducted well above the gas condensation temperature. In the case of $\mathrm{CO}_{2}$, the high-pressure isotherms were analogous to those obtained with $\mathrm{N}_{2}$ at low pressures (up to 1 bar) and $-196{ }^{\circ} \mathrm{C}$, because the relative pressure reached was 0.45 and some swelling can take place upon reaching these relative pressures. For $\mathrm{CO}_{2}$, however, all of the trapped gas was easily released on returning to $\mathrm{P} / \mathrm{P}_{0}=0$.

Moreover, the $\mathrm{CO}_{2}$ adsorption experiments at high pressure permit a better determination of the total micropore volume of the PPNs by applying the DR equation, because the $\mathrm{N}_{2}$ molecules cannot access to the narrowest micropores, as commented on above. However, the $\mathrm{CO}_{2}$ molecules can be adsorbed in the whole microporosity range; if a high enough relative pressure is achieved. The volumes determined from $\mathrm{CO}_{2}$ sorption at lowpressure $/ 0{ }^{\circ} \mathrm{C}$ and high-pressure $/ 25^{\circ} \mathrm{C}, \mathrm{V}_{\text {nmicro }}$ and $\mathrm{V}_{\text {micro }}(\mathrm{HP})$, respectively (Table 2 ), were similar for Triptycene-Isatin, indicating that the pore size distribution was much narrower than for the other three PPNs and, moreover, it was mainly formed by pores having diameters lower than $0.7 \mathrm{~nm}$. For the other three networks, the $\mathrm{V}_{\text {micro }}(\mathrm{HP})$ was higher than $\mathrm{V}_{\text {nmicro }}$ showing that the pore size distribution was clearly wider and more heterogeneous. However, it is to be pointed out that the values of $\mathrm{V}_{\text {micro }}(\mathrm{HP})$ were similar to those of $\mathrm{V}_{\text {micro, }}$ obtained from low-pressures $\mathrm{N}_{2}$ isotherms, for the TFAP-based PPNs, indicating 
that their microporosity was mainly due to pores with diameters higher than $0.45-0.50$ nm.
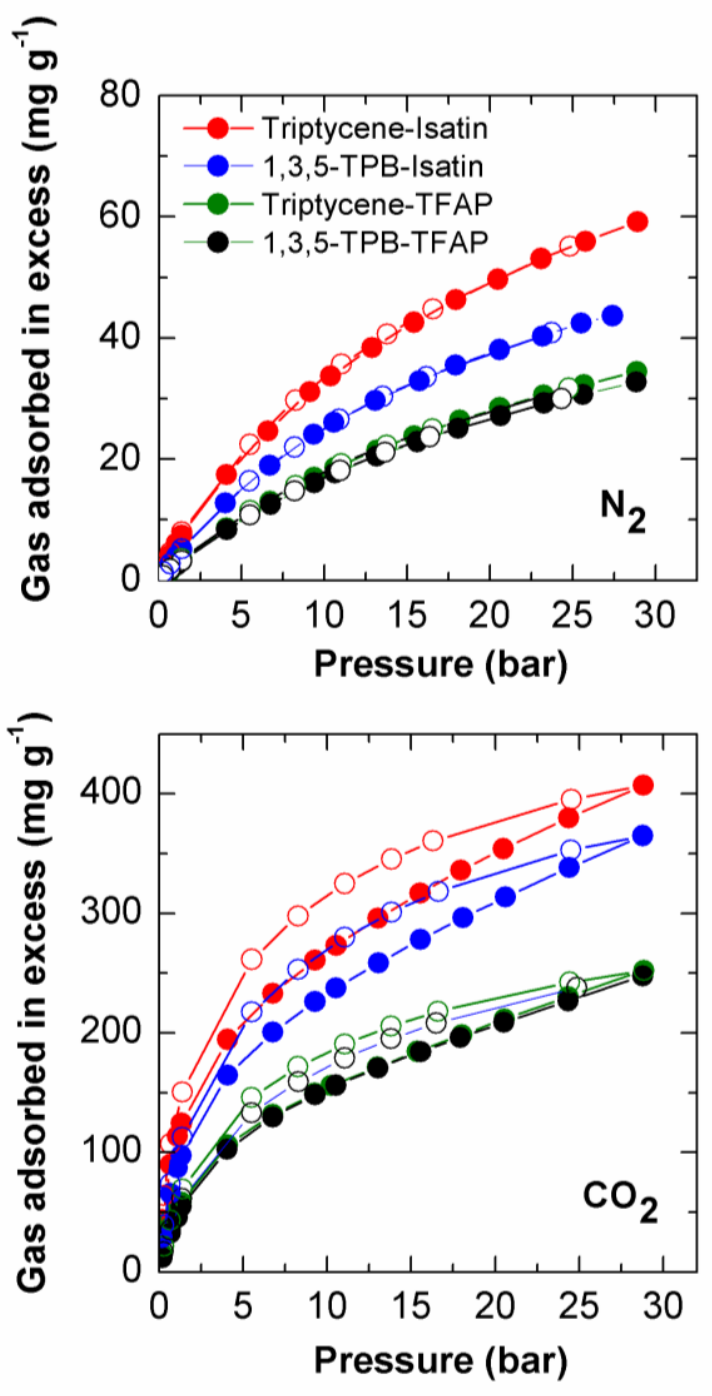

Figure 11. $\mathrm{N}_{2}$ and $\mathrm{CO}_{2}$ adsorption desorption isotherms of PPNs at $25{ }^{\circ} \mathrm{C}$ up to 30 bar.

Another way of seeing that the microporosity size distribution is different in these PPNs is by comparing the characteristics curves of the adsorption measurements for $\mathrm{CO}_{2}$ and $\mathrm{N}_{2}$, which have been included in the Supporting Information (Section 4, Figure S4). In all cases, the overlapping of the $\mathrm{CO}_{2}$ characteristic curves at low and high pressures was observed. However, the curves obtained from $\mathrm{N}_{2}$ adsorption only overlapped with those corresponding to the high-pressure $\mathrm{CO}_{2}$ adsorption at low values of $(A / \beta)^{2}$ (i.e. high $\mathrm{P} / \mathrm{P}_{0}$ ), 
indicating the diffusional limitations of the $\mathrm{N}_{2}$ to access at the narrowest pores, as commented on previously. This effect was notable in the case of Triptycene-Isatin, where a large deviation was observed even at very low values of $(A / \beta)^{2}$ (around $300 \mathrm{~kJ}^{2} \mathrm{~mol}^{-2}$ ), significantly lower than in the other PPNs, confirming its narrower porosity.

\section{5. $\mathrm{CO}_{2} / \mathrm{N}_{2}$ Selectivity}

Because these PPNs, and particularly those derived from isatin, showed high physicochemical stability and relatively good $\mathrm{CO}_{2}$ storage capacity, we have studied their ability to selectively capture $\mathrm{CO}_{2}$ over $\mathrm{N}_{2}$. As commented on above, $\mathrm{N}_{2}$ was much less adsorbed than $\mathrm{CO}_{2}$, up to 30 bar and $25^{\circ} \mathrm{C}$, which would be indicative of a good selectivity of $\mathrm{CO}_{2}$ over $\mathrm{N}_{2}$.

In a first attempt to evaluate the use of these PPNs as solid adsorbents in the capture of $\mathrm{CO}_{2}$ from post-combustion flue gas, ${ }^{60-63}$ the selectivity on a binary gas mixture $\left(\mathrm{CO}_{2} / \mathrm{N}_{2}\right)$ was estimated by applying the SIPs adsorption model, which allows predicting the selectivity from single component isotherms. Detailed information about the calculations performed at high pressures and $25^{\circ} \mathrm{C}$ can be seen in the Supporting Information (Section 5). Figure 12 shows the $\mathrm{CO}_{2} / \mathrm{N}_{2}$ selectivity for binary mixtures with different $\mathrm{CO}_{2}$ molar fraction (between 0.05 and 0.25 ) and pressure varying from 1 to 15 bar. The predicted selectivity for all the PPNs decreased when either the $\mathrm{CO}_{2}$ mole fraction in the mixture or the pressure increased. The selectivity to separate $\mathrm{CO}_{2} / \mathrm{N}_{2}$ from a mixture with a composition similar to those of flue gases $(15 / 85 \%)$ and 1 bar pressure was 29.5 for Triptycene-Isatin, 32.7 for 1,3,5-TPB-Isatin, 28.6 for Triptycene-TFAP, and 22.5 for 1,3,5-TPB-TFAP.

In general, the performance in terms of $\mathrm{CO}_{2}$ capacity and $\mathrm{CO}_{2} / \mathrm{N}_{2}$ selectivity were comparable, or even superior, to those of other microporous materials, such as porous 
organic materials ${ }^{23,53,54}$, carbon based materials, ${ }^{64}$ and zeolitic imidazolate frameworks, ${ }^{65}$ for similar flue gas composition and temperature and pressure conditions.
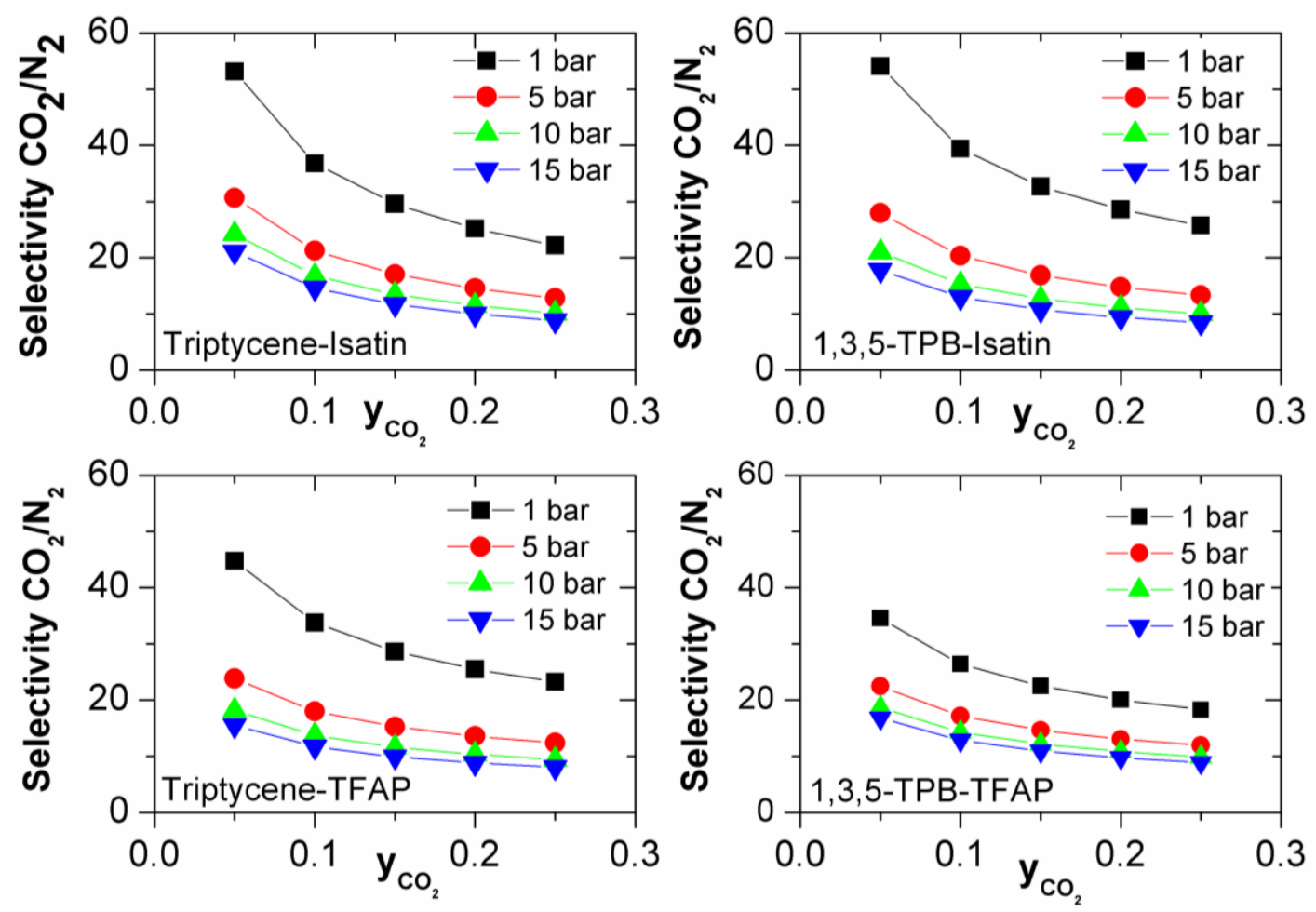

Figure 12. Selective adsorption of $\mathrm{CO}_{2}$ over $\mathrm{N}_{2}$ in a mixture of both gases at $25^{\circ} \mathrm{C}$ and different pressures as a function of the $\mathrm{CO}_{2}$ mole fraction.

\section{CONCLUSIONS}

A new set of porous polymer networks (PPNs) from rigid trifunctional aromatic monomers and ketone derivatives were successfully prepared in quantitative yield using a cost-effective and feasible methodology, which is easily scaled up to produce large quantities of material for practical applications.

The PPNs were amorphous microporous materials with moderate surface areas (between 580 and $790 \mathrm{~m}^{2} \mathrm{~g}^{-1}$ ), good chemical stability and exceptional thermal resistance, even in air, with onset of degradation temperatures above $420{ }^{\circ} \mathrm{C}$. 
The PPNs derived from isatin showed the highest $\mathrm{CO}_{2}$ uptake together with the highest values of $Q_{\text {st. }}$ This indicates a favorable chemical interaction between $\mathrm{CO}_{2}$ and the lactam moieties, which has been confirmed by quantum mechanical calculations. However, if both PPNs from isatin are compared, the $\mathrm{CO}_{2}$ uptake is significantly higher for the Triptycene-Isatin network. Therefore, the difference between both networks has to be attributed to their microporosity characteristics, because both have the same value of $V_{\text {total }}$ and $\mathrm{V}_{\text {micro }}$ but Triptycene-Isatin PPN has a significantly higher contribution of narrow micropores to the total microporosity ( $82 \%$ of the total pore volume, versus $64 \%)$.

Because of the above, the $\mathrm{CO}_{2}$ uptake for Triptycene-Isatin and the $\mathrm{CO}_{2} / \mathrm{N}_{2}$ selectivity under post-combustion capture conditions was comparable to those of the best PPNs reported up to now. The combination of these properties with the stability and synthetic feasibility commented on above, make them very promising as industrial $\mathrm{CO}_{2}$ adsorbents.

\section{SUPPORTING INFORMATION}

Details on the calculations made from gas sorption measurements and on the quantum mechanical calculations. This material is available free of charge via the internet at http://pubs.acs.org.

\section{AUTHOR INFORMATION}

\section{Corresponding Author}

* E.mail: 1ozano@ictp.csic.es and cristina.alvarez@ictp.csic.es.

\section{Author contributions}

\section{ORCID}

Beatriz Lopez-Iglesias: 0000-0003-0198-1368

Fabián Suárez-García: 0000-0002-1970-293X 
Carla Aguilar-Lugo: 0000-0003-4700-1564

Alfonso González Ortega: 0000-0002-9226-7807

Camino Bartolomé: 0000-0002-8492-6825

Jesús M. Martínez-Ilarduya: 0000-0003-4561-1131

José G. de la Campa: 0000-0003-1882-3104

Ángel E. Lozano: 0000-0003-4209-3842

Cristina Álvarez: 0000-0002-5000-0776

The research work was made through contributions of all authors.

The manuscript was written through contributions of Cristina Álvarez, José G. de la Campa, Ángel E. Lozano and Fabian Suárez-García.

\section{Funding Sources}

This research was financially supported by Spain's MINECO (Projects MAT2013-45071R, MAT2016-76413-C2-R1, MAT2016-76413-C2-R2, and CTQ2016-80913-P and CTQ2014-52796-P). We are also indebted to the Spanish Junta de Castilla y León for its funding help (Projects VA248U13 and VA051P17).

\section{Notes}

The authors declare no competing financial interest.

\section{ACKNOWLEDGMENT}

Authors acknowledge Manuel Avella-Romero for the SEM images taken at the SEMTEM Microscopy Facilities of the University of Valladolid, and Dr. Leví López for the NMR spectra carried out at the Solid State NMR facilities of ICTP-CSIC. C. Aguilar- 
Lugo kindly acknowledges a Mexico's grant (264013 CONACYT postdoctoral fellowship).

\section{REFERENCES}

(1) Stocker, T.; Dahe, Q.; Plattner, G. -K.; Tignor, M.; Midgley, P. IPCC Expert Meeting on Assessing and Combining Multi Model Climate Projections. Meeting Report. National Center for Atmospheric Research: Boulder, Colorado, USA, 2010.

(2) Cao, L.; Caldeira, K. Atmospheric Carbon Dioxide Removal: Long-Term Consequences and Commitment. Environ. Res. Lett. 2010, 5, 24011-24016.

(3) Bodansky, D. The Durban Platform Negotiations: Goals and Options. Harvard Project on climate Agreements Viewpoint 2012. https://ssrn.com/abstract=2102994.

(4) Weber, E. U. Experience-Based and Description-Based Perceptions of Long-Term Risk: Why Global Warming Does Not Scare Us (Yet). Climatic Change 2006, 77, 103120.

(5) Paterson, N. R. Global Warming: a Critique of the Anthropogenic Model and its Consequences. Geosci. Can. 2011, 38, 41-48.

(6) Kim, K. S. Public Understanding of the Politics of Global Warming in the News Media: the Hostile Media Approach. Public Underst. Sci. 2011, 20, 690-705.

(7) Haszeldine, R. S. Carbon Capture and Storage? How Green can Black Be. Science 2009, 325, 1647-1652.

(8) Sneddon, G.; Greenaway, A.; Yiu, H. H. P. The Potential Applications of Nanoporous Materials for the Adsorption, Separation, and Catalytic Conversion of Carbon Dioxide. Adv. Energy Mater. 2014, 4, 1301873-1301891. 
(9) Dawson, R.; Cooper, A. I.; Adams, D. J. Nanoporous Organic Polymer Networks. Prog. Polym. Sci. 2012, 37, 530-563.

(10) McKeow, N. B.; Budd, P. M. Exploitation of Intrinsic Microporosity in PolymerBased Materials. Macromolecules 2010, 43, 5163-5176.

(11) Das, S.; Heasman, P.; Ben, T; Qiu, S. Porous Organic Materials: Strategic Design and Structure-Function Correlation. Chem. Rev. 2017, 117, 1515-1563.

(12) Zhu, G.; Ren, H. Porous Organic Frameworks; Springer, Berlin, Heidelberg, 2015.

(13) Saleh, M.; Lee, H. M.; Kemp, K. C.; Kim, K. S. Highly Stable $\mathrm{CO}_{2} / \mathrm{N}_{2}$ and $\mathrm{CO}_{2} / \mathrm{CH}_{4}$ Selectivity in Hyper-Cross-Linked Heterocyclic Porous Polymers. ACS Appl. Mater. Interfaces 2014, 6, 7325-7333.

(14) Puthiaraj, P.; Ahn, W. S. $\mathrm{CO}_{2}$ Capture by Porous Hyper-Cross-Linked Aromatic Polymers Synthesized Using Tetrahedral Precursors. Ind. Eng. Chem. Res. 2016, 55, 7917-7923.

(15) Dawson, R.; Stöckel, E.; Holst, J. R.; Adams, D. J.; Cooper A. I. Microporous Organic Polymers for Carbon Dioxide Capture. Energy Environ. Sci. 2011, 4, 4239-4245. (16) Ben, T.; Pei, C.; Zhang, D.; Xu, J.; Deng, F.; Jing, X.; Qiu, S. Gas Storage in Porous Aromatic Frameworks (PAFs). Energy Environ. Sci. 2011, 4, 3991-3999.

(17) Ben, T.; Ren, H.; Ma, S.; Cao, D.; Lan, J.; Jing, X.; Wang, W.; Xu, J.; Deng, F.; Simmons, J. M.; Qiu, S.; Zhu. G. Targeted Synthesis of a Porous Aromatic Framework with High Stability and Exceptionally High Surface Area. Angew. Chem. Int. Ed. 2009, 48, 9457-9460. 
(18) Chen, L.; Honsho, Y.; Seki, S.; Jiang, D. Light-Harvesting Conjugated Microporous Polymers: Rapid and Highly Efficient Flow of Light Energy with a Porous Polyphenylene Framework as Antenna. J. Am. Chem. Soc. 2010, 132, 6742-6748.

(19) Li, L.; Cai, K.; Wang, P.; Ren, H.; Zhu, G. Construction of Sole Benzene Ring Porous Aromatic Frameworks and Their High Adsorption Properties. ACS Appl.Mater.Interfaces 2015, 7, 201-208.

(20) Lu, W.; Yuan, D.; Zhao, D.; Schilling, C. I.; Plietzsch, O.; Muller, T.; Bräse, S.; Guenther, J.; Blümel, J.; Krishna, R.; Li, Z.; Zhou, H. -C. Porous Polymer Networks: Synthesis, Porosity, and Applications in Gas Storage/Separation. Chem. Mater. 2010, 22 , $5964-5972$.

(21) Lu, W.; Sculley, J. P; Yuan, D.; Krishna, R.; Wei, Z.; Zhou, H.-C. PolyamineTethered Porous Polymer Networks for Carbon Dioxide Capture from Flue Gas. Angew. Chem. Int. Ed. 2012, 51, 7480-7484.

(22) Katsoulidis, A. P.; Kanatzidis, M. G. Phloroglucinol Based Microporous Polymeric Organic Frameworks with $-\mathrm{OH}$ Functional Groups and High $\mathrm{CO}_{2}$ Capture Capacity. Chem. Mater. 2011, 23, 1818-1824.

(23) Rabbani G. M.; El-Kaderi, H. M. Synthesis and Characterization of Porous Benzimidazole-Linked Polymers and Their Performance in Small Gas Storage and Selective Uptake. Chem. Mater. 2012, 24, 1511-1517.

(24) Sekizkardes, A. K.; Altarawneh, S.; Kahveci, Z.; İslamoğlu, T.; El-Kaderi, H. M. Highly Selective $\mathrm{CO}_{2}$ Capture by Triazine-Based Benzimidazole-Linked Polymers. Macromolecules 2014, 47, 8328-8334. 
(25) Rabbani, M. G.; Islamoglu, T.; El-Kaderi, H. M. Benzothiazole- and BenzoxazoleLinked Porous Polymers for Carbon Dioxide Storage and Separation. J. Mater. Chem. A 2017, 5, 258-265.

(26) Zhu, Y.; Long, H.; Zhang, W. Imine-Linked Porous Polymer Frameworks with High Small Gases $\left(\mathrm{H}_{2}, \mathrm{CO}_{2}, \mathrm{CH}_{4}, \mathrm{C}_{2} \mathrm{H}_{2}\right)$ Uptake and $\mathrm{CO}_{2} / \mathrm{N}_{2}$. Chem. Mater.2013, 25, 16301635.

(27) Kuhn, P.; Antonietti, M.; Thomas, A. Porous, Covalent Triazine-Based Frameworks Prepared by Ionothermal Synthesis. Angew. Chem. Int. Ed. 2008, 47, 3450-3453.

(28) Wang, K.; Huang, H.; Liu, D.; Wang, C.; Li, J.; Zhong, C. Covalent Triazine-Based Frameworks with Ultramicropores and High Nitrogen Contents for Highly Selective $\mathrm{CO}_{2}$ Capture. Environ. Sci. Technol. 2016, 50, 4869-4876.

(29) Ren, S.; Bojdys , M. J.; Dawson, R.; Laybourn, A.; Khimyak, Y. Z.; Adams, D. J.; Cooper, A. I. Porous, Fluorescent, Covalent Triazine-Based Frameworks via RoomTemperature and Microwave-Assisted Synthesis. Adv. Mater. 2012, 24, 2357-2361.

(30) Ghanem, B. S.; Msayib, D. J.; McKeown, N. B.; Harris, K. D. M.; Pan, Z.; Budd, P. M.; Butler, A.; Selbie, J.; Book, D.; Walton, A. A Triptycene-Based Polymer of Intrinsic Microporosity that Displays Enhanced Surface Area and Hydrogen Adsorption. Chem. Commun. 2007, 0, 67-69.

(31) Grzybowski, M.; Skonieczny, K.; Butenschön, H.; Gryko, D. T. Comparison of Oxidative Aromatic Coupling and the Scholl Reaction. Angew. Chem. Int. Ed. 2013, 52, 9900-9930.

(32) Li, L.; Ren, H.; Yuan, Y.; Yu, G.; Zhu, G. Construction and Adsorption Properties of Porous Aromatic Frameworks via $\mathrm{AlCl}_{3}$-Triggered Coupling Polymerization. J. Mater. Chem. A. 2014, 2, 11091-11098. 
(33) Msayib, K. J.; McKeown, N. B. Inexpensive Polyphenylene Network Polymers with Enhanced Microporosity. J. Mater. Chem. A. 2016, 4, 10110-10113.

(34) Surya Prakash, G. K.; Panja, C.; Shakhmin, A.; Shah, E.; Mathew, T.; Olah, G. A. $\mathrm{BF}_{3}-\mathrm{H}_{2} \mathrm{O}$ Catalyzed Hydroxyalkylation of Aromatics with Aromatic Aldehydes and Dicarboxaldehydes: Efficient Synthesis of Triarylmethanes, Diarylmethyl benzaldehydes, and Anthracene Derivatives. J. Org. Chem. 2009, 74, 8659-8668.

(35) Preis, E.; Widling, C.; Scherf, U.; Patil, S.; Brunklaus, G.; Schmidt, J.; Thomas, A. Aromatic, Microporous Polymer Networks with High Surface Area Generated in FriedelCrafts-Type Polycondensations. Polym. Chem. 2011, 2, 2186-2189.

(36) Olah, G. A. Superelectrophiles. Angew. Chem. Int. Ed. 1993, 32, 767-788.

(37) Klumpp, D. A. Superelectrophiles: Charge-Charge Repulsive Effects. Chem. Eur. J. 2008, 14, 2004-2015.

(38) O'Connor, M. J.; Boblak, K. N.; Topinka, M. J.; Kindelin, P. J.; Briski, J. M.; Zheng, C.;. Klumpp, D. A. Superelectrophiles and the Effects of Trifluoromethyl Substituents. $J$. Am. Chem. Soc. 2010, 132, 3266-3267.

(39) Kray, W. D.; Rosser, R. W. Synthesis of Multifunctional Triarylfluoroethanes. 1. Condensation of Fluoro Ketones. J. Org. Chem. 1977, 42, 1186-1189.

(40) Colquhoun, H. M.; Zolotukhin, M. G.; Khalilov, L. M.; Dzhemilev, U. M. Superelectrophiles in Aromatic Polymer Chemistry. Macromolecules 2001, 34, 11221124.

(41) Zolotukhin, M. G.; Fomina, L.; Salcedo, R.; Sansores, L.E.; Colquhoun, H. M.; Khalilov, L. M. Superelectrophiles in Polymer Chemistry. A Novel, One-Pot Synthesis of High-Tg, High-Temperature Polymers. Macromolecules 2004, 37, 5140-5141. 
(42) Zolotukhin, M. G.; Fomine, S.; Lazo, L. M.; Salcedo, R.; Sansores, L. E.; Cedillo,

G. G.; Colquhoun, H. M.; Fernandez-G, J. M.; Khalizov, A. F. Superacid-Catalyzed Polycondensation of Acenaphthenequinone with Aromatic Hydrocarbons. Macromolecules 2005, 38, 6005-6014.

(43) Nieto, D. R.; Zolotukhin, M. G.; Fomina, L.; Fomine, S. Superacid Mediated Hydroxyalkylation Reaction of 1,2,3-Indanetrione: a Theoretical Study. J. Phys. Org. Chem. 2010, 23, 878-884.

(44) Pulido, B. A.; Waldron, C.; Zolotukhin, M. G.; Nunes, S. P. Porous Polymeric Membranes with Thermal and Solvent Resistance. J. Memb. Sci. 2017, 539, 187-196.

(45) Sircar, S. Measurement of Gibbsian Surface Excess. AlChE J. 2001, 47, 1169-1176.

(46) Suárez-Ruiz, I.; Juliao, T.; Suárez-García, F.; Marquez, R.; Ruiz, B. Porosity Development and the Influence of Pore Size on the $\mathrm{CH}_{4}$ Adsorption Capacity of a Shale Oil Reservoir (Upper Cretaceous) from Colombia. Role of Solid Bitumen. Int. J. Coal Geol. 2016, 159, 1-17.

(47) Thommes, M.; Kaneko, K.; Neimark, A. V.; Olivier, J. P.; Rodriguez-Reinoso, F.; Rouquerol, J.; Sing, K. S. W. Physisorption of Gases, with Special Reference to the Evaluation of Surface Area and Pore Size Distribution (IUPAC Technical Report). Pure Appl. Chem. 2015, 87, 1051-1069.

(48) Weber, J.; Antonietti, M.; Thomas, A. Microporous Networks of High-Performance Polymers: Elastic Deformations and Gas Sorption Properties. Macromolecules 2008, 41, $2880-2885$.

(49) Jeromenok, J.; Weber, J. Restricted Access: On the Nature of Adsorption/Desorption Hysteresis in Amorphous, Microporous Polymeric Materials. Langmuir 2013, 29, 1298212989. 
(50) Lozano-Castelló, D.; Cazorla-Amorós, D.; Linares-Solano, A. Usefulness of $\mathrm{CO}_{2}$ Adsorption at $273 \mathrm{~K}$ for the Characterization of Porous Carbons. Carbon 2004, 42, $1233-$ 1242.

(51) Rouquerol, F.; Rouquerol, J.; Sing, K. S. W. Adsorption by Powders \& Porous Solids. Principles, Methodology and Applications, Academic Press, New York, 1999.

(52) Jagiello, J.; Thommes, M. Comparison of DFT Characterization Methods Based on $\mathrm{N}_{2}, \mathrm{Ar}, \mathrm{CO}_{2}$, and $\mathrm{H}_{2}$ Adsorption Applied to Carbons with Various Pore Size Distributions. Carbon 2004, 42, 1225-1229.

(53) Arab, P.; Rabbani, M. G.; Sekizkardes, A. K.; İslamoğlu, T.; El-Kaderi, H. M. Copper (I)-Catalyzed Synthesis of Nanoporous Azo-Linked Polymers: Impact of Textural Properties on Gas Storage and Selective Carbon Dioxide Capture. Chem. Mater. 2014, $26,1385-1392$.

(54) Mondal, S.; Das, N. Triptycene based 1,2,3-Triazole Linked Network Polymers (TNPs): Small Gas Storage and Selective $\mathrm{CO}_{2}$ Capture. J. Mater. Chem. A. 2015, 3, 23577-23586.

(55) Zhao, Y-C.; Cheng, Q.-Y.; Zhou, D.; Wang, T.; Han, B-H. Preparation and Characterization of Triptycene-Based Microporous Poly(Benzimidazole) Networks. $J$. Mater. Chem. 2012, 22, 11509-11514.

(56) Zhang, C.; Liu, Y.; Li, B.; Tan, B.; Chen, C. -F.; Xu, H. -B.; Yang, X. -L. Triptycene-Based Microporous Polymers: Synthesis and their Gas Storage Properties. ACS Macro Lett. 2012, 1, 190-193.

(57) Li, G.; Wang, Z. Microporous Polyimides with Uniform Pores for Adsorption and Separation of $\mathrm{CO}_{2}$ Gas and Organic Vapors. Macromolecules 2013, 46, 3058-3066. 
(58) Islamoglu, T.; Behera, S.; Kahveci, Z.; Tessema, T. -D.; Jena, P.; El-Kaderi, H. M. Enhanced Carbon Dioxide Capture from Landfill Gas Using Bifunctionalized Benziimidazole-Linked Polymers. ACS Appl. Mater. Interfaces 2016, 8, 14648-14655.

(59) Thirion, D.; Rozyyev, V.; Park, J.; Byun, J.; Jung, Y.; Atilhan, M.; Yavuz, D. T. Observation of the Wrapping Mechanism in Amine Carbon Dioxide Molecular Interactions on Heterogeneous Sorbents. Phys. Chem. Chem. Phys. 2016, 18, 1417714181.

(60) Boot-Handford, M. E.; Abanades, J. C.; Anthony, E. J.; Blunt, M. J.; Brandani, S.; Dowell, N. M.; Fernández, J. R.; Ferrari, M-C.; Gross, R.; Hallett, J. P.; Haszeldine, R. S.; Heptonstall, P.; Lyngfelt, A.; Zen Makuch, Z.; Mangano, E.; Richard T. J. Porter, R. T. J.; Pourkashanian, M.; Rochelle, G. T.; Shah, N.; Joseph G. Yao, J. Y.; Paul S. Fennell, P. S. Carbon Capture and Storage Update. Energy Environ. Sci. 2014, 7, 130-189.

(61) Wang, Q.A.; Luo, J. Z.; Zhong, Z. Y.; Borgna, A. $\mathrm{CO}_{2}$ Capture by Solid Adsorbents and their Applications: Current Status and New Trends. Energy Environ. Sci. 2011, 4, $42-55$.

(62) Olajire, A. A. $\mathrm{CO}_{2}$ Capture and Separation Technologies for End- of-Pipe Applications - a Review. Energy 2010, 35, 2610-28.

(63) Espinal, L.; Poster, D. L.; Wong-Ng, W.; Allen, A. J.; Green, M. L. Measurement, Standards, and Data Needs for $\mathrm{CO}_{2}$ Capture Materials: A Critical Review. Environ. Sci. Technol. 2013, 47, 11960-11975.

(64) Radosz, M.; Hu, X.; Krutkramelis, K.; Shen, Y.; Flue-Gas Carbon Capture on Carbonaceous Sorbents: Towards a Low-Cost Multifunctional Carbon Filter for "Green" Energy Producers. Ind. Eng. Chem. Res.2008, 47, 3783-3794. 
(65) Banerjee, R.; Furukawa, H.; Britt, D.; Knobler, C.; O'Keeffe, M.; Yaghi, O. M. Control of Pore Size and Functionality in Isoreticular Zeolitic Imidazolate Frameworks and their Carbon Dioxide Selectivity Capture Properties. 